\title{
Pathophysiology of Acute IIIness and Injury
}

\author{
Sergio Arlati
}

\section{Key Points}

- The inflammatory reaction is a highly adaptive, integrated response with a global protective effect against microbial pathogens or tissue damage. It provides for the elimination of pathogens, removal of cellular debris, and promotes tissue repair and healing.

- Multiple trauma or severe infection causes a widespread inflammatory reaction that causes diffuse endothelial activation (chemotaxis), damage (permeability edema), and vasodilation (hypotension-shock).

- Inflammation and coagulation are strictly coupled. As a general rule hyperinflammation means hypercoagulability. Coagulation has beneficial effects when inflammation is localized, but it becomes catastrophic when disseminated intravascular coagulation ensues.

- Humoral inflammatory mediators include cytokines, complement, thrombin, acute phase proteins, kinins, and PAF. Endothelial cells, monocytes, antigenpresenting cells (macrophages and dendritic cells), and neutrophils are the main effector cells.

- Neutrophils are responsible for tissue damage. Their widespread activation accounts for the noxious effects to innocent tissues with multiple organ damage.

- A counter-inflammatory response mounts immediately after the hyperinflammatory reaction. Such response is proportionate to inflammation along the whole course of disease.

- An immediate decrease of the acquired (lymphocytic) immune response occurs in parallel with

\section{S. Arlati $(\bowtie)$}

Anesthesia and Intensive Care 1 (1st Dept),

ASST Grande Ospedale Metropolitano Niguarda, Milan, Italy

e-mail: sergio.arlati@ospedaleniguarda.it inflammation leading to dysfunction and progressive immunoparalysis.

- Apoptosis of the cells of the immune system is the main responsible of immunoparalysis. This exposes to increased risks for opportunistic infections and sepsis/septic shock.

\subsection{Basic Concepts}

The pathophysiology of acute care illnesses is a generalized, multi-systemic process that invariably activates the immuneinflammatory and coagulation systems with production of diffuse tissue and organ damage. The temporal development of acute care illnesses is quite variable although it usually evolves as a multiphasic process or more rarely as a single acute event that the body can't cope with. For example, multiple trauma causes the activation of the immuneinflammatory, coagulation, and neuroendocrine systems. Thus ischemia-reperfusion that follows severe post-traumatic hemorrhage with hypotension and tissue hypoperfusion activates the immune-inflammatory system with adhesion of polymorphonuclear leukocytes (PMNs) to the endothelium and increased capillary permeability, plasma fluid leakage, and tissue edema. The widespread activation of the coagulation creates a prothrombotic milieu with deposition of microthrombi, diffuse capillary obstruction, and further ischemic damage. Similarly, severe pneumonia challenges the circulating monocytes and resident tissue macrophages with a broad spectrum of microbial molecules. The subsequent activation of the inflammatory and coagulation systems causes the widespread activation of the endothelium with production of either local (e.g., ARDS) or distant organ damage (multiple organ dysfunction syndrome, MODS). However, the immune system provides a counter-regulatory response that limits the deleterious effects of the generalized inflammatory activation 
(compensatory anti-inflammatory response syndrome, CARS) [1]. Although CARS opposes to the systemic inflammatory response syndrome (SIRS) [2], this is a double-edged sword because the risk of septic complications is increased. If unresolved, SIRS and CARS become the underlying players of a catabolic syndrome that leads to MODS and ultimately death [3]. In the past SIRS was viewed as an exaggerated response to inflammatory stimuli, but the latest experimental and observational data indicate that it is a rather predictable side effect of especially severe morbid events. In practice, SIRS and CARS result from the growing sophistication of ICU care that keeps patients alive during the early (acute) phase of traumatic and septic diseases. The protracted survival of formerly rapid lethal conditions makes now appreciable their natural evolution. Recent acquisitions also suggest that SIRS and CARS develop simultaneously rather than in sequence as previously believed. As a result a mixed antagonist response syndrome (MARS) was coined to reflect the balance between SIRS and CARS [4] (Fig. 2.1).

However, the phenotypic predominance of the hyperinflammatory state is the rule in early sepsis, hypoxia, or trauma as influenced by antigenic load, microbial virulence, host genetic factors, age, nutritional status, and comorbidities [5]. In the past CARS was believed to develop after SIRS exhaustion by repeated noxious stimuli (second hit theory) $[5,6]$. According to this theory, recurrent morbid insults augment the inflammatory response by repeated stimulation of the inflammatory cascade. In this sense, SIRS would no longer depend by the initial insult but rather by the intensity and frequency of subsequent hits. However, the continuous challenge of the inflammatory system mounts an antiinflammatory response that ultimately becomes predominant. So CARS does not develop simultaneously with SIRS, but only a minimal overlap would exist between the two phe- nomena. This pathophysiological view is derived from the observation that CARS prevails in the later stages of disease when the increased susceptibility to infections is associated with a weakened pro-inflammatory response (SIRS exhaustion). This concept translated into the linear transition from acute (early) SIRS to chronic (late) CARS with possible alternating recurrence of the two phases (MARS), (Fig. 2.2).

However, this view is no longer accepted as the historical belief of the "cytokine storm" after a catastrophic acute illness (e.g., meningococcal sepsis) giving the spectacular inflammatory reaction is not the rule [7]. Instead, the most common picture is by far a patient over 65 years of age with sepsis or recovering from multiple trauma/surgery and evidence of immunosuppression without the typical exaggerated acute phase inflammatory response [7]. In the past "cytokine storm" was synonymous of SIRS that is hyperinflammation defined by excessive release of classical proinflammatory cytokines including IL1, IL6, IL8, and TNF $\alpha$. However, this concept is too narrow as it was quickly noted that "cytokine storm" is not the typical occurrence in late (chronic) sepsis or even in acutely septic patients with a weakened immune system [8, 9]. Similarly, it seems incorrect to define CARS on the basis of elevated release of antiinflammatory cytokines in the blood. The current concept is rather that the magnitude of cytokine release depends on the premorbid immune-inflammatory status of the patient [10]. Otherwise stated the healthier the patient, the stronger will be the release of cytokines after stimulus. As a corollary, the more protracted is the disease, the more faded will be the inflammatory response over time (e.g., recurrent sepsis in postsurgical or trauma patient). However, an acute inflammatory response although typical of the acute phase may occur at any time of the disease profile if the host is sufficiently immunologically responsive. This view holds for
Fig. 2.1 Temporal profile of pro-inflammatory and anti-inflammatory cytokines according to the most recent hypothesis of simultaneous development of SIRS and CARS. So MARS is always ongoing

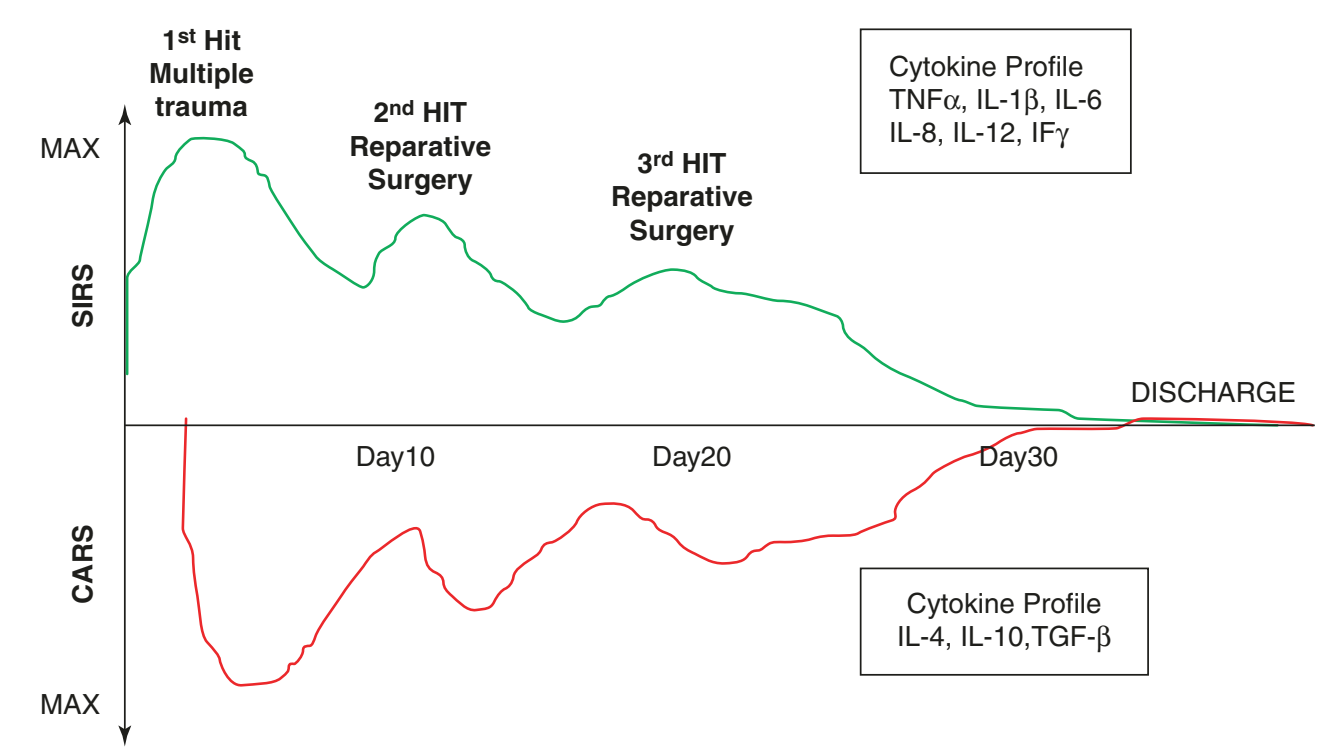


Fig. 2.2 Temporal profile of pro-inflammatory and anti-inflammatory cytokines according to the hypothesis of sequential development of SIRS and CARS. MARS is a transitional state in-between them

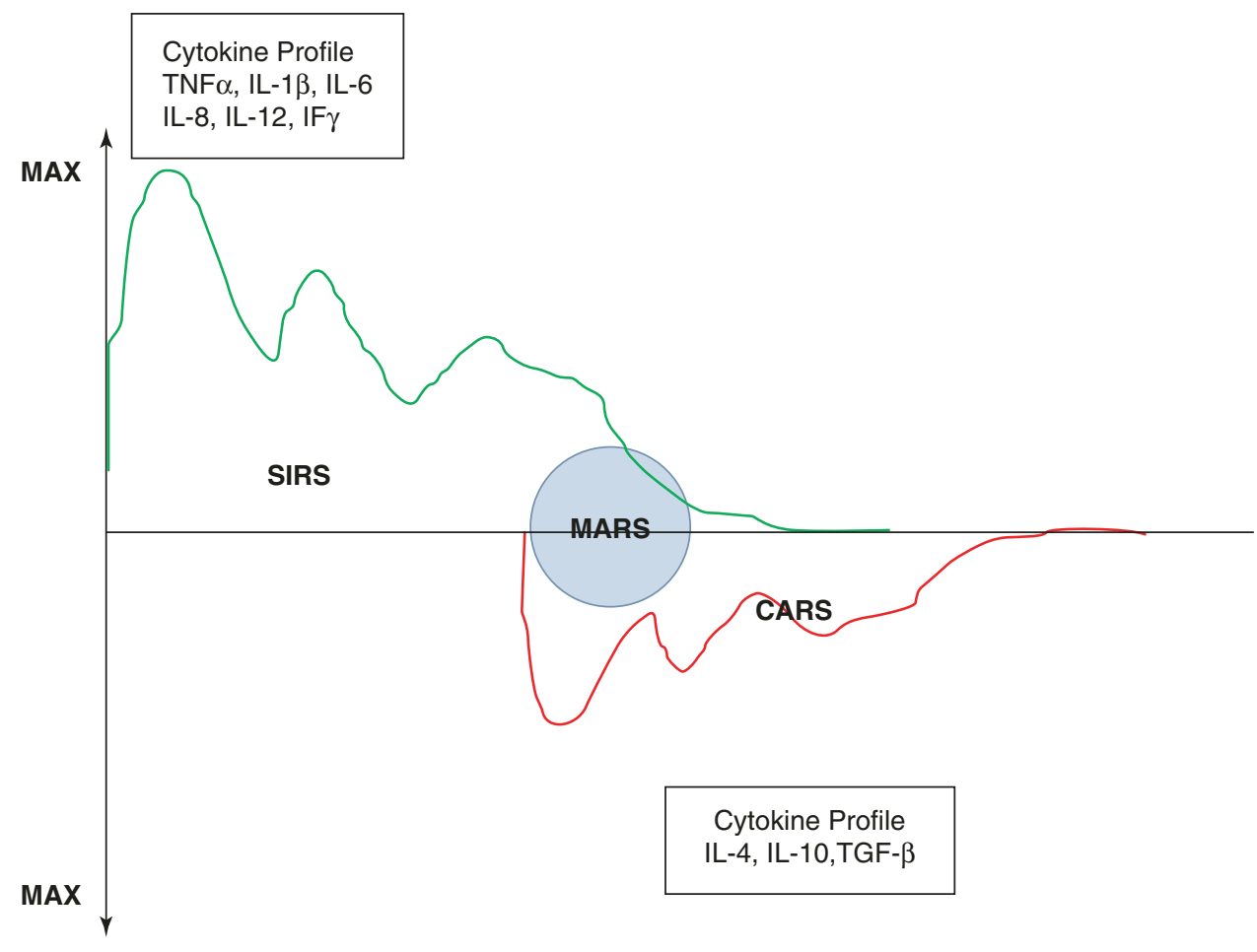

both the pro-inflammatory and anti-inflammatory cytokines, so it is incorrect to define the patient's inflammatory status on the basis of his/her cytokine profile [10]. Therefore, the mixed cytokine response pattern better represents the patient's inflammatory status leading to the paradigm "Sepsis: Always in MARS" [11]. Thus a hyperinflammatory status at the onset of sepsis or multiple trauma reflects the ability of the host to release a great amount of proinflammatory and anti-inflammatory mediators. Such ability is destined to fade over time with progression to a late (chronic) inflammatory status. In recent years, the immunocompetent cells have emerged as a new relevant player for the appearance of immunosuppression or immunoparalysis that often characterizes the host's response during the more chronic disease stages. At present, the process of immunosuppression (decreased T-cell proliferation and production of IL2, decreased monocyte and macrophage function) is believed to occur in parallel with the hyperinflammatory status of early sepsis of traumatic or surgical origin [12, 13]. Animal studies indicate that in non-survivors, the immune cell suppression progresses indefinitely up to anergy from the very beginning to the more chronic stages in a timeindependent manner [10]. As a result, the phenotype of immunosuppression does not often correspond to the cytokine pattern of peripheral blood.

Prior to early deaths, cellular immunosuppression develops rapidly together with high pro-inflammatory and antiinflammatory cytokine release (MARS-like) [14]. Conversely, the chronic state is preceded by a progressive (subacute or chronic) impairment of immune cells function with robust pre-lethal signs of anergy and a deteriorating but MARS-like cytokine profile (simultaneous presence of both pro-inflammatory and anti-inflammatory mediators in the blood) [10]. The spread of the inflammatory process starting from a single organ or tissue is by far the most frequent event in the pathophysiology of acute diseases. The inflammatory response is a highly coordinated process, which has evolved to limit the spread of noxious stimuli, eliminates pathogens and necrotic cellular debris, and promotes the healing of damaged tissues. It is subjected to multiple activations and control mechanisms and whose efficiency is largely dependent on genetic predisposition, age, and neurovegetative and hormonal milieu derived from the stress response. Finally, inflammation and immunity are tightly related in a complex network of multiple interconnections and reverberating loops. However, extremely intense or repeated stimulations may disturb their tuned response so that the inflammatory mediators spill over the anatomical barriers and multiple organs dysfunction syndrome ensues. Cardinal inflammation phenomena are local vasodilation, increased endothelial permeability, and chemotactic cells activation from the natural (granulocytes and monocytes) and acquired immune system (lymphocytes). The vascular mechanisms that lead to the four cardinal signs of inflammation are resumed in Fig. 2.3.

Neutrophils and monocytes are activated to infiltrate the site of infection with subsequent phagocytosis and lysis of bacterial products or cellular debris. In the meanwhile, the activated coagulation system seals the site of inflammation and provides a meshwork of fibrin that helps in the reparation process. Therefore, increased membrane permeability, 
Fig. 2.3 Vascular mechanisms at the origin of the cardinal signs of inflammation. Arteriolar vasodilation and increased permeability are responsible for augmentation of blood flow (redness and heat) and fluids accumulation in tissue (swelling and pain)

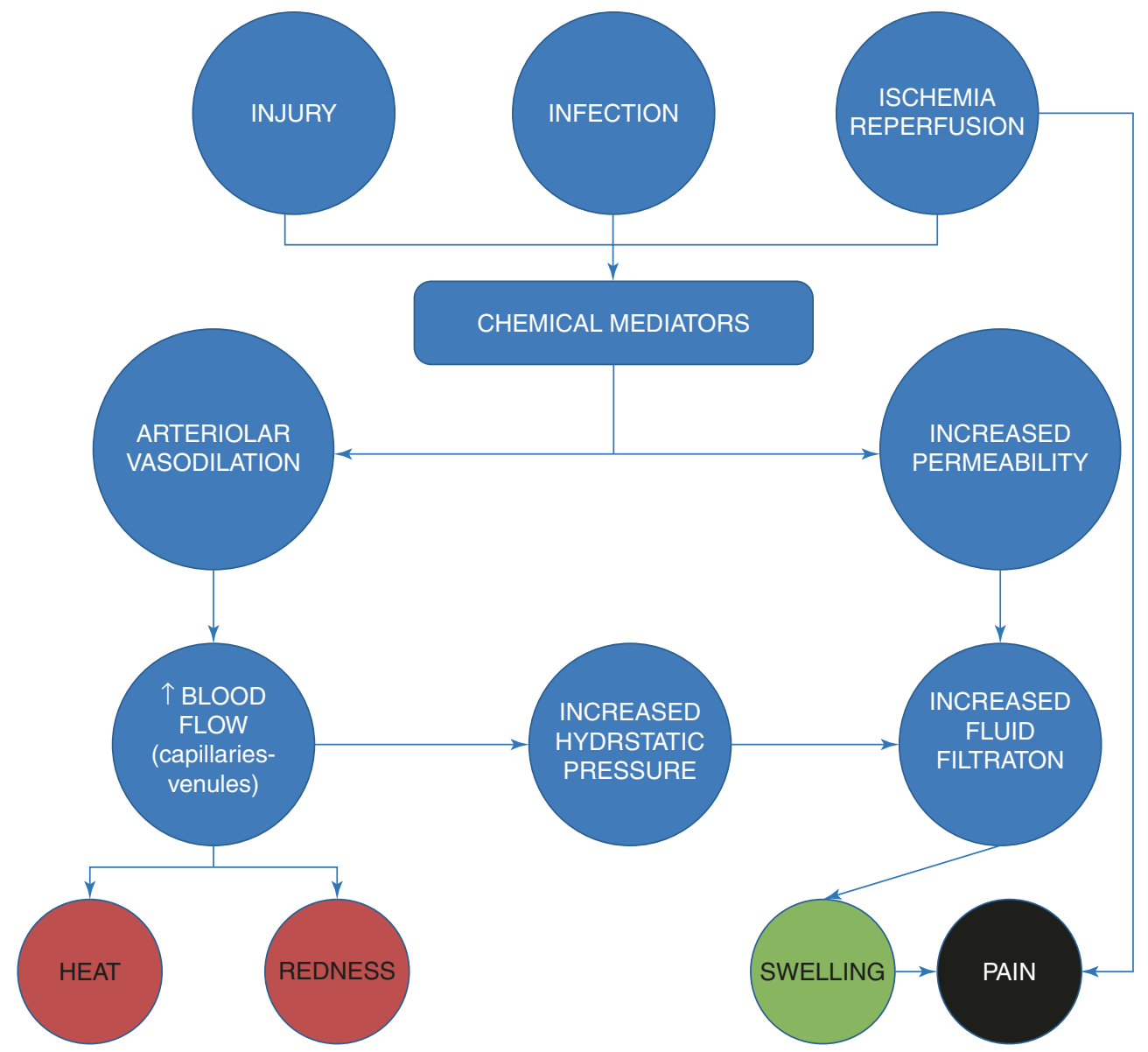

capillary vasodilation, chemotaxis, and phagocytosis are defensive mechanisms that act in concert to ensure the maximum of protection against any threat or danger. A multiplicity of cell types (e.g., endothelium, monocytes, platelets) as well as humoral factors (complement, leukotrienes, kinins) acts following a synergistic and often redundant logic to activate, propagate, and maintain the inflammation so that the host defense is guaranteed. Nevertheless, the uncontrolled diffusion of inflammatory mediators causes hypotension and tissue edema by generalized vasodilation and increased endothelial permeability. Furthermore, the diffuse deposition of microthrombi by disseminated intravascular coagulation worsens the oxygen supply to tissues this, in turn, contributing to ischemic cells damage, further inflammation (ischemia/reperfusion injury), and MODS. The local action of the inflammatory system is similar to a well-refined military strategy. After an enemy attack (e.g., trauma) that engages the local garrison (resident macrophages and glial cells), the combat zone is rapidly enclosed and sealed by reinforcement troops (chemotactic activation of PMNs and intravascular coagulation). Thereafter, the soldiers get into the battlefield (increased membrane permeability and leukocytes migration) and shoot at the enemy destroying him (phagocytosis, proteases, and toxic oxygen products). However, after a massive attack, the hurried and often disorganized mobilization of the reserve troops makes difficult or even impossible to implement an effective defense. The recruitment of soldiers is often chaotic and uncoordinated (widespread chemotactic activation), the effective concentration of troops is impossible (generalized increase of endothelial permeability), and military patrols often shoot at innocent people (organ damage). Thus, pneumococcal pneumonia can transform into severe sepsis or septic shock if a generalized inflammatory reaction develops by either cellular (neutrophils, monocytes, macrophages, endothelium) or humoral effectors (complement, contact phase proteins, leukotrienes, cytokines, chemokines) resulting into increased capillary permeability (tissue edema), vasodilation (hypotension), and coagulation activation (ischemic organ damage). Generally, the pathophysiological mechanisms that lead to a systemic inflammatory reaction are infections, trauma, and ischemiareperfusion damage. Each of them can act by itself or in combination with the other two. For example, multiple trauma causes the activation of immune-inflammatory mechanisms by itself (tissue necrosis), or as a consequence of ischemia-reperfusion damage (e.g., gut ischemia by post- 
traumatic mesenteric hematoma or post-ischemic muscular tissue reperfusion after hemorrhagic shock). Apart from the abovementioned mechanisms, the uncontrolled activation of the immune system (autoimmune diseases), massive cytokines production (metastatic cancer, leukemia, or lymphoma), and the unrestrained activation of serum proteases (acute pancreatitis) are less frequent causes of generalized inflammatory activation.

\subsection{How the Systemic Inflammatory Reaction Develops}

The widespread activation of the inflammatory system (systemic inflammatory reaction syndrome, SIRS) originates from the site of trauma, infection, or hypoxic cell damage (ischemia/reperfusion). Infection, traumatic or hypoxic injury, causes the release of a heterogeneous pattern of endogenous and exogenous molecules that trigger the innate immune system as chemoattractants and activators of antigen-presenting cells.

\subsubsection{Alarmins}

Infection from bacterial, viral, and fungal agents releases signaling substances that are recognized by the innate immune system due to their characteristic molecular pattern (pathogen-associated molecular patterns, PAMPs) [15]. Conversely, traumatic or hypoxic cell injury releases the so-called damage-associated molecular patterns (DAMPs) [16, 17] which represent the correlate of PAMP for danger signals of endogenous origin. PAMPs and DAMPs are grouped into the larger family of "alarmins" in assignment to the term danger signals [15]. Otherwise stated PAMPs and DAMPs constitute a physiologic signaling system that alerts the body to the presence of foreign invaders or noxious stimuli. "Alarmins" activate specific receptors of the superfamily of the Toll-like receptors (TLRs) [18, 19], expressed on endothelial and innate immune cells like macrophages, dendritic cells (antigenpresenting cells, APCs), monocytes, and PMNs [20]. APCs act as an intermediate between innate and acquired immune system. Their main function is to process antigen material and to present it to effector $\mathrm{T}$ cells of the immune system. TLR receptors recognize a variety of peptides that are important signaling molecules for activation and production of a multiplicity of inflammatory mediators. In addition, DAMPs are potent activators of the complement system [21-23] whose anaphylatoxins attract monocytes and PMNs on the endothelium. The high mobility group box protein (HMGB) is one of the most studied "alarmin." $\mathrm{HMBG}$ is a protein molecule derived from the nucleus of damaged cells $[15,24]$. It is released by activated myeloid cells (e.g., neutrophils) [20], macrophages, dendritic cells [25-27], or necrotic cells [26] and acts as a chemoattractant for monocytes, macrophages, dendritic cells, neutrophils, and $\Upsilon \delta$ cells [3]. It also participates to the secretion of proinflammatory cytokines [28] and mediates the monocyteendothelial interaction by increasing vascular leakage [24, 29]. Fragments of DNA and histones are other well-known potent "alarmins." They originate from damaged tissues and microbial digestion by resident tissue macrophages or activated neutrophils. Peptides and mitochondrial DNA are vigorous alert molecules probably because of their vestigial origin from intracellular bacteria [3].

\subsubsection{Pro-inflammatory Phospholipase Pathway}

In addition to "alarmins," the release of phospholipids by damaged cell membranes (cellular hypoxia and trauma) or exogenous lipopolysaccharides (e.g., LPS-endotoxin) and polymers (lipoteichoic acid and peptidoglycans) alert the innate immune system by activating the complement and the contact phase proteins system (FXII, kallikrein, and kininogen). Phospholipids activate the phospholipases $\mathrm{A}_{2}$ and $\mathrm{C}$ [30] with the production of arachidonic acid metabolites as leukotriene $\mathrm{B}_{4}$, prostaglandin $\mathrm{E}_{2}$, and thromboxane $\mathrm{A}_{2}$ [31]. The activation pathway of phospholipase $\mathrm{A}_{2}$ and $\mathrm{C}$ is detailed in Fig. 2.4.

In addition, mast cells release histamine and bradykinin with resulting vasodilation and increased capillary permeability and edema [32]. Just 20-30 min after trauma or microbial invasion, the innate immune cells become activated, Fig. 2.5.

\subsubsection{Innate Cellular Immune Defense}

The first line of the innate immune defense is represented by PMNs, mostly neutrophils, and monocytes. PMNs are chemoattracted by locally produced cytokines (e.g., TNF- $\alpha$ ), leukotrienes, platelet-activating factor (PAF), and complement fragments (c5a) [33-36]. These inflammatory mediators also activate PMNs to express adhesion surface molecules for appropriate ligands on the activated endothelium [37]. This receptor-ligand interaction allows for adhesion of leukocytes to the capillary wall. Thereafter PMNs migrate through the endothelial barrier into the tissues by opportune signaling receptors on the inner surface of the endothelium. In the meanwhile, resident macrophages secrete cytokines (TNF $\alpha$ and IL-1) and chemokines (IL-8) which help the immune and inflammatory cells in selfregulating and crosstalking each other. 


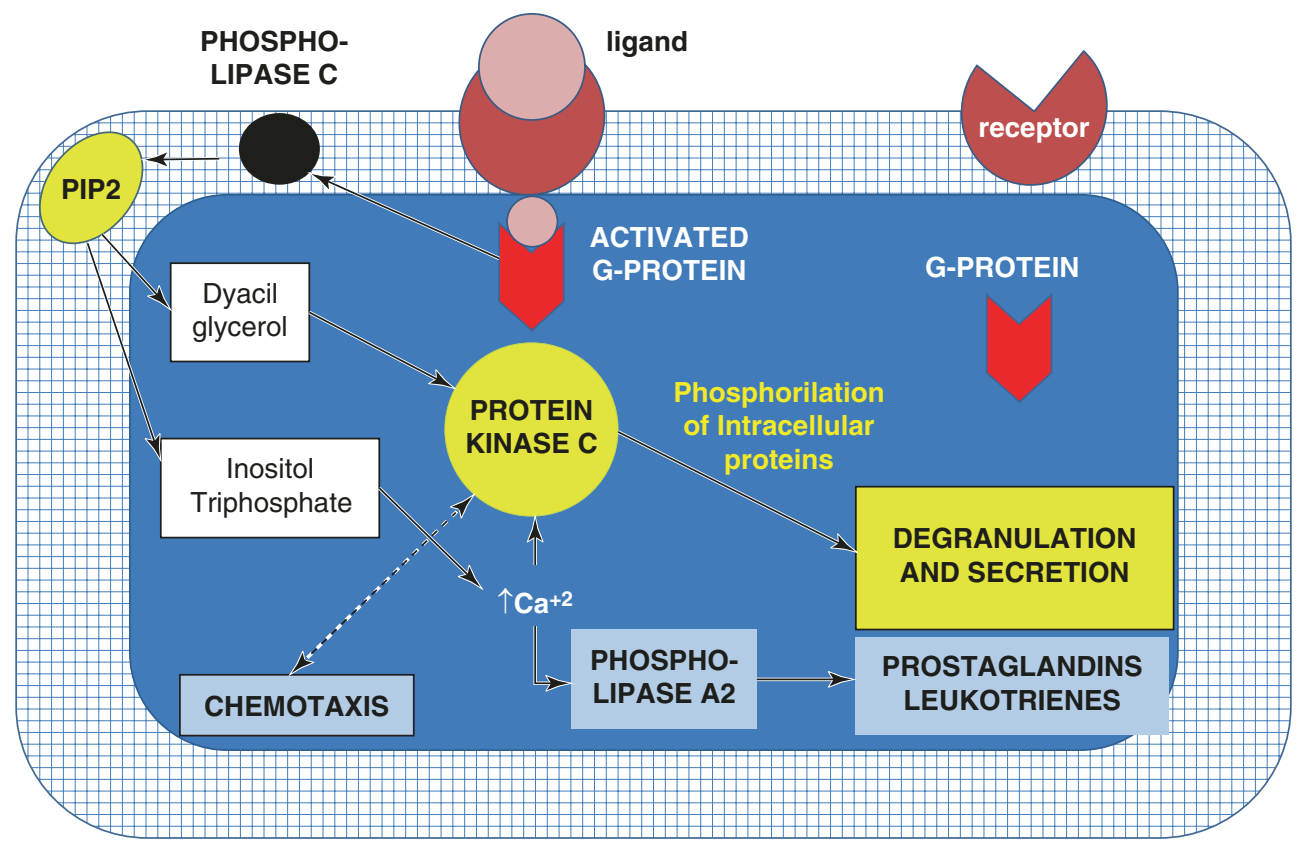

Fig. 2.4 Metabolic pathways of phospholipase $\mathrm{A}_{2}$ and C. After ligand binding to the appropriate receptor, $\mathrm{G}$ protein is activated, this in turn activating the membrane phospholipase $\mathrm{C}$ to cleave phosphatidylinositol (PIP2) into diacylglycerol (DAG) and inositol triphosphate. DAG subsequently activates protein kinase $\mathrm{C}$ to promote phosphorylation of intracellular proteins that in turn leads leukocytes to degranulate and secrete proteases and other toxic substances. Conversely inositol triphosphate induces the mobilization of calcium ions from storage pools with subsequent activation of phospholipase $\mathrm{A}_{2}$ by a $\mathrm{Ca}^{2+}$-dependent mechanism. Phospholipase $\mathrm{A}_{2}$ catalyzes the synthesis of prostaglandins and leukotrienes by arachidonic acid
Fig. 2.5 Main humoral and cellular steps of the hyperinflammatory immune response

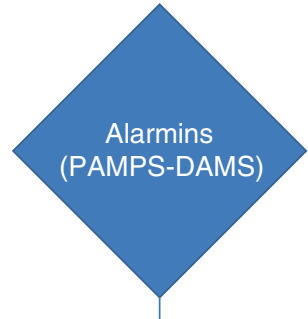

Complement

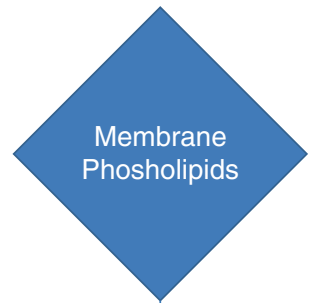

Prostaglandins-Tromboxane Leukotrienes

Toll-like receptors

$\checkmark$

\section{CHEMOATTRACTION}

(Monocytes-Neutrophils), (Macrophages Dendritic cells)

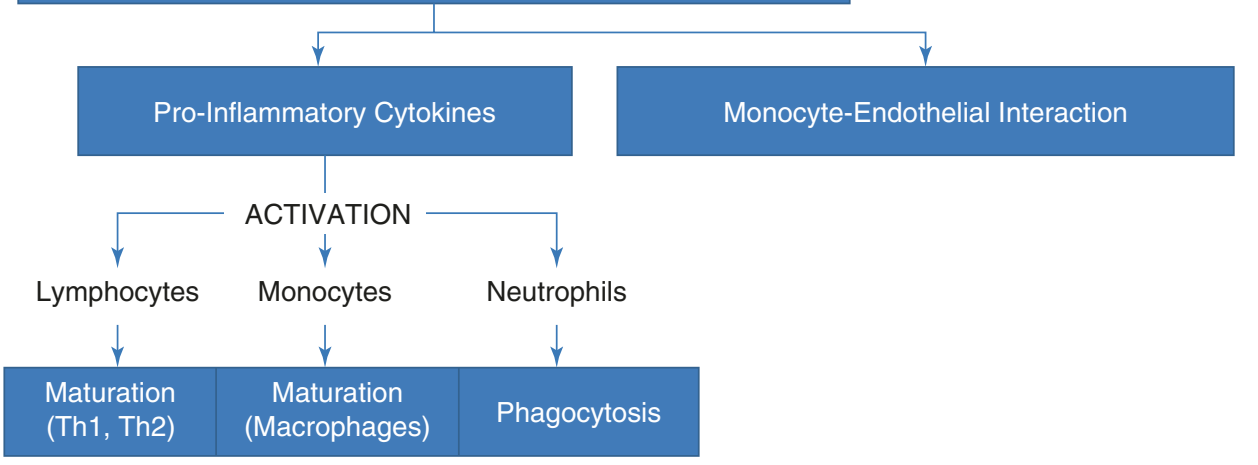




\subsubsection{Pro-inflammatory Cytokines}

Cytokines and chemokines are pleiotropic molecules with a great variety of effects that act in a paracrine and autocrine fashion. Among the most important cytokines secreted in the hyper-acute phase, TNF- $\alpha$ and IL- $1 \beta$ act within $1-2 \mathrm{~h}$ after trauma or sepsis, while IL-6, IL-10, and the chemokine IL-8 are subacute mediators [38]. Among the most relevant properties of cytokines, there is the ability to activate monocytes (innate immune system) and lymphocytes (acquired immune system) [39]. Under the appropriate cytokine pattern, the circulating monocytes differentiate into resident macrophages, while lymphocytes mature into different cell lines having immune-stimulatory (Th-1), immune-depressant (Th-2), and immune-modulatory (Treg) action [40]. Pro-inflammatory cytokines trigger both the recruitment and the phagocytic activity of leukocytes [41]. They also stimulate the release of proteases and increase the production of free oxygen radicals from activated neutrophils [41].

1. One of the best characterized cytokines is TNF which can produce SIRS when injected experimentally in high doses [39]. Its actions include the stimulation of many cell types and survival or apoptosis [42], cytokine secretion (IL-6, IL-8, IFY, IL-10), activation of the arachidonic acid pathways (thromboxane A2 and prostaglandin E2) and nitric oxide, induction of fever and production of selectins, and PAF (see below). TNF secretion is stimulated by many physiological stresses (hemorrhage, hypoxemia) as well as ischemia-reperfusion, endotoxin, and complement system. Macrophages and monocytes are the main TNF producers, although activated $\mathrm{T}$ cells are also implicated. Tumor necrosis factor acts via its receptors TNFR1 and TNFR2 with effects that depend on the specific receptor binding and environmental factors influence. Binding of TNF- $\alpha$ to TNFR1 leads to transcription of pro-inflammatory genes via the NF-Kb transcription factor. However, TNFR1 possesses a death domain at the cytoplasmic tail so that its stimulation also induces apoptosis via the caspase enzymes cascade (see below). Although these two effects seem contradictory, they might represent an adaptive mechanism that has evolved to protect cells against excessive stimulation (see below: Kidney Dysfunction). In contrast to the almost ubiquitous TNF1R, TNFR2 is expressed on immune and endothelial cells only and becomes activated by membrane-bound TNF- $\alpha[42,43]$. Binding to TNFR2 leads to activation and proliferation of neutrophils and many immune cells as NK cells, B cells, and peripheral T cells [44].
2. Interleukin-1-beta is the other well-studied cytokine that acts synergistically with TNF- $\alpha$. Its actions include fever induction, cytokine and chemokine secretion [45], T cell and macrophage stimulation and various inflammatory mediators (including adhesion molecules), acute phase proteins, and NO synthesis. It also induces the release of neutrophils from the bone marrow and stimulates the expression of proteases and metalloproteases by tissues. IL- $1 \beta$ is secreted by macrophages, monocytes, and endothelial cells. Stimuli for IL-1 $\beta$ include TNF, complement, endotoxin, hemorrhage, and ischemia. The effects of IL- $1 \beta$ are mediated by the type IL- 1 receptor (IL-1RI) which belongs to the IL-1 receptor superfamily. Besides IL-1 $\beta$, another molecule that binds IL-1RI is the so-called soluble IL-1 receptor antagonist (IL1-RA) suggesting a controlling role in IL-1-mediated immune response.

3. The third important cytokine in the early inflammatory response is IL-6. Its secretion is induced by TNF and IL-1 [46]. Although it does not induce SIRS when injected into experimental animals, IL-6 has vasodilatory properties as it induces the production of nitric oxide by the endothelial cells. IL-6 is a subacute cytokine with marked regulatory properties on immune cell growth and differentiation. It inhibits apoptosis of neutrophils and stimulates the hepatic acute phase protein synthesis but also exhibits an anti-inflammatory action [47] by inducing the release of soluble TNFR and IL-1RA [48]. It seems, therefore, to play a dual role in the inflammatory response by acting both as a pro-inflammatory and anti-inflammatory mediator [49, 50]. Clinical studies demonstrated increased plasma levels in non-survivor septic patients so that IL-6 has been proposed as a prognostic marker [51-53].

4. The chemokine IL- 8 is the most powerful chemoattractant for PMNs and monocytes [54]. Chemokines control the traffic of the immune cells, which are the main effectors of the immune system. Their binding to G-protein-coupled receptors leads to dose-dependent effects including chemotaxis and activation of immune cells. After stimulation by IL- 1 , TNF- $\alpha$, complement, microbial products (e.g., LPS), hypoxia, and reperfusion, IL-8 increases neutrophils degranulation, adherence, and chemotaxis. Interestingly, chemokines act as chemoattractants in lower doses and potent activators of immune cells function in higher doses. Recently a group of so-called silent chemokine receptors has been described suggesting a role as decoy or scavenger receptors. The Duffy antigen receptors for chemokines (DARC), first described as blood group antigen, have been shown to bind IL- 8 and other chemokines thus suggesting a regulatory action against excessive leukocyte activation in the systemic circulation [39]. 
Table 2.1 Main cellular source and effects of pro-inflammatory cytokines

\begin{tabular}{|l|l|l|l|l|}
\hline Name & $\begin{array}{l}\text { Main source } \\
\text { TNF- } \alpha\end{array}$ & $\begin{array}{l}\text { Immune cells activation } \\
\text { Monocytes } \\
\text { T cells }\left(\mathrm{T}_{\mathrm{H}} 1\right)\end{array}$ & Macrophages, monocytes, NK cells & $\begin{array}{l}\text { Immune-inflammatory mediators } \\
\text { Cytokines, NO, arachidonic acid metabolites, PAF, } \\
\text { selectins, adhesion molecules }\end{array}$ \\
\hline IL-1 & $\begin{array}{l}\text { Macrophages } \\
\text { Monocytes } \\
\text { Endothelial } \\
\text { cells }\end{array}$ & Macrophages, T cells & $\begin{array}{l}\text { Cytokines, chemokines, acute phase proteins, tissue } \\
\text { proteases, adhesion molecules }\end{array}$ \\
\hline IL-6 & $\begin{array}{l}\text { Macrophages } \\
\text { Monocytes } \\
\text { Endothelial } \\
\text { cells }\end{array}$ & $\begin{array}{l}\text { Growth and differentiation of T and B } \\
\text { T-cells, NK cells }\end{array}$ & Release of TNFR and IL-1RA, acute phase proteins \\
\hline IL-8 & $\begin{array}{l}\text { Macrophages } \\
\text { Monocytes } \\
\text { Any somatic } \\
\text { cell }\end{array}$ & $\begin{array}{l}\text { Activation and chemotaxis of immune } \\
\text { cells }\end{array}$ & Leukotrienes, PAF \\
\hline
\end{tabular}

The cellular source and the main effects of pro-inflammatory cytokines are resumed in Table 2.1.

\subsubsection{Local and Systemic Inflammatory Mediators}

Apart from cytokines, other important mediators of the hyper-acute phase are the arachidonic acid metabolites (leukotrienes, prostaglandins, and thromboxane). They are responsible for the activation of PMNs and endothelium and platelet aggregation. These substances are generated by activation of the phospholipases $\mathrm{A} 2$ and $\mathrm{C}$ (PLA 2 and PLC) which follows the entry of $\mathrm{Ca}^{2+}$ ions into damaged cells. $\mathrm{PLA}_{2}$ also induces the release of PAF from the endothelium. PAF is an important inflammatory mediator with marked effects on macrophages, endothelial cells, and platelets aggregation. The inflammatory response is promptly propagated and amplified by important circulating mediators as the complement system, the contact phase proteins (kallikrein-kinins), and the coagulation cascade.

1. The complement cascade is a series of enzymatic cleavage reactions that are activated via the classical route by antigen-antibody complexes (IgM and $\mathrm{IgG}$ ) or alternatively by bacterial degradation products (e.g., LPS, endotoxin) [32, $55,56]$. The latter pathway does not require prior immunization and thus represents an immediate defense mechanism against microbes. Conversely, the "natural antibodies" activate the complement by forming antigen-antibody complexes with different molecular species from exogenous (microbial) or endogenous (necrotic cells) origin [57-59]. "Natural antibodies" are physiologically circulating antibodies that arise in serum independently from prior host immunization [60]. They are mainly produced by a subpopulation of $\mathrm{CD}^{+} \mathrm{B}$ cells and are poly-reactive with different antigens as peptides, phospholipids, and polysaccharides [60-62]. In musculoskeletal trauma and ischemia-reperfusion injury, the intense antigenic stimulation leads to binding of natural $\operatorname{IgM}$ antibodies and development of post-traumatic "innate autoimmunity" [63]. Complement activation leads to the formation of opsonins, anaphylatoxins, and the membrane attack complex, a multiprotein complex responsible for the increased capillary permeability [32]. Anaphylatoxins and opsonins are involved in important inflammatory processes such as opsonization, chemotaxis, and neutrophils degranulation. Complement also promotes the synthesis of acute phase proteins by the liver and stimulates the degranulation of mast cells with histamine release (vasodilation) [32, 64]. In practice, the activated complement is involved in all the most relevant inflammatory processes as immune cells attraction to the site of trauma or infection, microbial phagocytosis and lysis, antigens opsonization, platelets activation, and histamine release. The complement cascade is, therefore, a fundamental component of the innate host defense as it can be rapidly activated in a non-specific manner after injury or infection. It is phylogenetically ancient due to its basic role in the host response to bacterial pathogens. However, the systemic activation of the complement leads to severely deleterious effects such as shock and tissue edema due to massive vasodilation and increased membrane permeability.

2. Coagulation factor XII and kallikrein, together with kininogen, represent the contact phase system. These proteins activate each other by forming an integrated, highly amplified system for activation of the coagulation cascade. Kallikrein also stimulates the formation of the vasodilator bradykinin from kininogen. Kinins are potent vasodilators and vigorous effectors of increased vascular permeability [65]. A close interconnection exists between hemostasis and the inflammatory system. For example, the activated platelets aggregate with circulating leuko- 
cytes to stimulate the immune cells system with production of endothelial damage [66]. Platelets also release pro-inflammatory mediators that excite the immune system [67] thus creating a vicious circle that produces more and more SIRS. The activated coagulation cascade after trauma or infection is primarily intended to stop the loss of blood and to seal the lesion. Thereafter, phagocytic and immune cells eliminate necrotic cells and invading microbes. However, the uncontrolled activation of the coagulation cascade causes the widespread deposition of microthrombi, this in turn causing hypoxic cellular damage and increased risk for hemorrhagic complications due to consumption of platelets and coagulation factors [6871]. Disseminated intravascular coagulation (DIC) is a pathophysiological mechanism that frequently occurs after multiple trauma $[68,70,71]$ and severe infections $[68,70]$. DIC is responsible for diffuse microthrombi deposition, capillary blockade with heterogeneous microcirculatory perfusion, tissue ischemia, and production of hypoxic cellular damage [68, 72].

3. Acute phase proteins are synthesized in the liver by induction of the locally (Kupffer cells) produced cytokines (TNF- $\alpha$, IL1- $\beta$, and IL6). This process is amplified by circulating cytokines that spillover from injured or infected tissue (overflow theory). Acute phase proteins include C-reactive protein (CRP), $\alpha$-1-antitrypsin, $\alpha-2$ macroglobulin, ceruloplasmin, lipopolysaccharide-binding protein (LPB), fibrinogen, and prothrombin [73]. These proteins have several inflammatory and anti-inflammatory properties. For example, CRP increases the surface expression of tissue factor (TF) [74], a procoagulant membranebound $4.5 \mathrm{kD}$ protein on PMNs, monocytes, and tissue macrophages (see below). Conversely, $\alpha-1$-antitrypsin neutralizes leukocyte proteases and free oxygen radicals, while $\alpha$-2-macroglobulin and ceruloplasmin are inhibitory cofactors for the synthesis of cytokines [74]. Finally, high concentrations of LPB suppress LPS activity [75].

\subsubsection{Phagocytosis}

At this step of the inflammatory process, the injured or infected tissue is invaded by activated PMNs, mainly neutrophils that release proteases (elastase), exert their phagocytic and digestive properties (phagolysosomes), and produce free oxygen radicals (e.g., hydrogen peroxide) [76] and reactive NO species (e.g., peroxynitrite) [77]. Both neutrophils and macrophages kill bacteria. The first step involves phagocytosis of opsonized microbes. Opsonization means that bacteria are covered with host proteins (e.g., antibodies and complement fragments) and appropriately recognized by cell surface receptors such as TLR and receptors for the Fc portion of the immunoglobulins. The phagocytosed bacteria are typically inserted into a vacuole, the phagosome, which fuses with primary (azurophilic) or secondary granules to form phagolysosomes. Azurophilic granules contain antimicrobial proteases such as elastase and bactericidal/permeability increasing proteins, while secondary granules contain antiseptic peptides as lysozyme, lactoferrin, and metalloproteases. Fusion of granules with phagosomes creates a hostile environment that kills the pathogen (Fig. 2.6).

At the same time, the resident macrophages and circulating monocytes begin to phagocyte cellular and microbial
Fig. 2.6 Mechanism of phagocytic-cell destruction of bacteria. Opsonized bacteria bind to complement receptors (CRs) and FC receptors (FCRs) on the surface of phagocytic cells. Thereafter the bacterium is taken into the cytoplasm and included into a phagosome. The fusion of phagosome with specific and azurophilic granules gives a phagolysosome that destroys the bacterium by toxic and enzymatic digestion

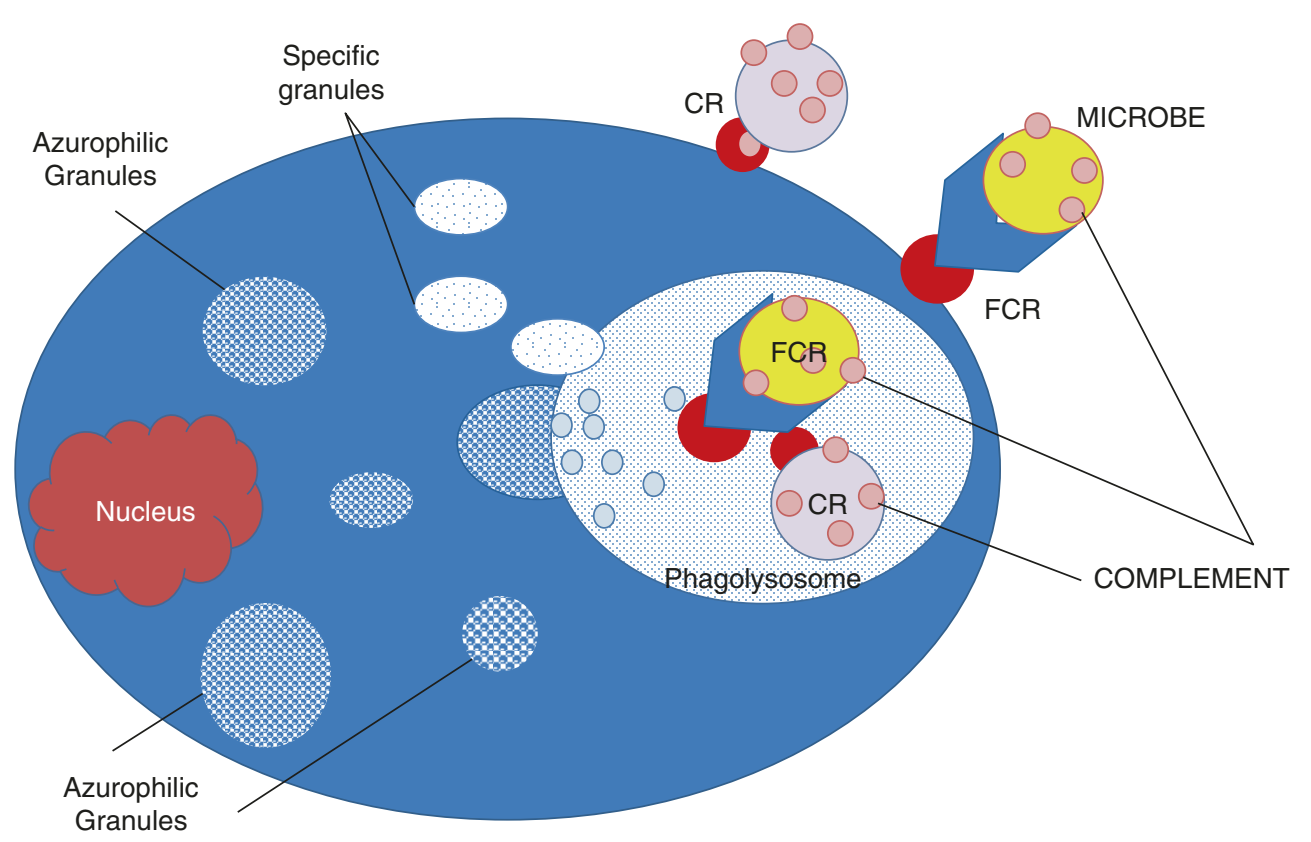


debris. These cells produce cytokines and express membrane surface antigens that originate from the digestion process (see Fig. 2.7 for details).

Such molecules activate the endothelium to express adhesion molecules for further neutrophils chemoattraction. In the meanwhile, macrophages interact with $\mathrm{T}$ helper cells $\left(\mathrm{CD} 4^{+}\right)$that secrete interferon $\Upsilon$ (IF $\Upsilon$ ) and other cytokines for phagocytic cells activation. Finally, their interaction with B lymphocytes produces antimicrobial antibodies. This is a highly coordinated process, able to eliminate foreign bodies or cellular debris so ensuring the most effective protection against any insult of whatever origin.

\subsection{The Anti-inflammatory Response}

Besides the plethora of pro-inflammatory mediators, many anti-inflammatory substances play a counter-regulatory role in the development of CARS. IL-4, IL-10, IL-13, and transforming-growth-factor $\beta$ (TGF- $\beta$ ) are among the most important anti-inflammatory and immunosuppressant mediators. The main actions of anti-inflammatory cytokines are shown in Table 2.2.

Besides these anti-inflammatory cytokines, several immune effector cells develop their actions immediately after the onset of the acute inflammatory response. The nature of their response is largely determined by the expressed membrane antigenic pattern as it determines their subsequent cellular interactions and biochemical reactions. From the native, multipotent $\mathrm{CD}^{+}{ }^{+} \mathrm{T}$ helper 0 cell (Th0), two main cell lines differentiate depending on cytokine environment, either into Th1 helper cell by IL-12 or Th2 helper cell by IL-4 [78].

1. The Th1 helper lymphocytes initiate and augment the delayed immune response by macrophage and neutrophil activation, promoting the production of opsonizing antibodies and stimulating the development of cytotoxic $\mathrm{T}$ cells. Their cytokines secretion includes IL-2, IFY, and TNF $\alpha$. IFY activates macrophages and iNOS to produce
Fig. 2.7 Antigen presenting cells recognize microbial infection by binding of pathogen-associated molecular patterns (PAMPs) to pattern recognition receptors (PRRs) as well as by phagocytosis of bacteria. Thereafter IL-12 is produced, and opportune co-stimulatory molecules (CD80/86) are expressed together with MHCII antigens that bind to corresponding T-cell ligands. T-cell activation and proliferation. The production of interferon $\gamma$ stimulates the macrophages to kill intracellular bacteria This binding results into

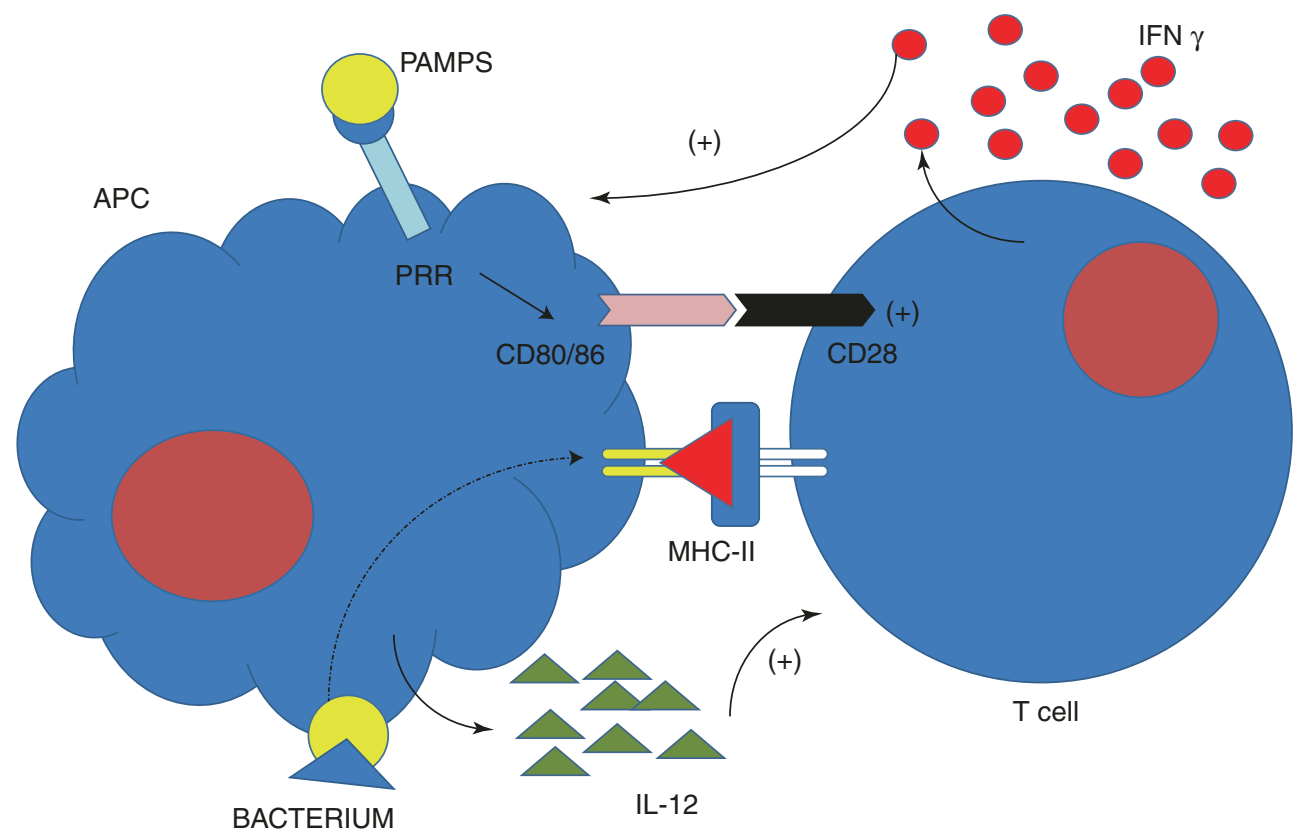

Table 2.2 Main cellular source and effects of anti-inflammatory cytokines

\begin{tabular}{l|l|l} 
Cytokine & Source & Actions \\
\hline IL-4 & T cells $\left(\mathrm{T}_{\mathrm{H}} 2\right)$, basophils, mast cells & T and B cells \\
\hline IL-10 & Monocytes/macrophages, $\mathrm{T}$ cells $\left(\mathrm{T}_{\mathrm{H}} 2, \mathrm{~T}_{\mathrm{reg}}\right)$ & Inhibits monocyte/macrophage activation \\
\hline IL-13 & T cells $\left(\mathrm{T}_{\mathrm{H}} 2\right)$ & Inhibits monocyte/macrophage cytokine production \\
\hline TGF- $\beta$ & Monocytes, $\mathrm{T}$ cells $\left(\mathrm{T}_{\mathrm{H}} 2, \mathrm{~T}_{\text {reg }}\right)$ & Inhibits monocyte/macrophage proliferation and activation \\
\hline IL-1RA & Hepatocytes, monocytes/macrophages, PMNs & Inhibits IL-1 action by blocking the IL-1 receptor
\end{tabular}


NO free radicals [79]. Th1 helper cells are therefore involved in the classical inflammatory response. Overactivation of Th1-type cells produces type 4 delayed hypersensitivity.

2. Conversely, Th2-type lymphocytes show marked antiinflammatory properties by producing anti-inflammatory cytokines as IL-4, IL-5, IL-10, and IL-13 [80]. Overactivation causes type 1 IgE-mediated allergy and hypersensitivity.

Other important players of the cell-mediated immune response in trauma and sepsis are the regulatory $\mathrm{T}$ (Tregtype) cells and T17-type cells.

3. Treg-type cells formerly known as suppressor $\mathrm{T}$ cells are modulator and deactivator of the immune response. They are immunosuppressive and generally downregulate the activation and proliferation of effector $T$ cells ( $T$ cells that responds to a stimulus including helper and killer lymphocytes). Treg-type cells produce IL-10 and TGF $\beta$ a potent anti-inflammatory cytokine. Elevated levels of circulating Treg cells have been observed in the blood of immune-paralyzed infected patients [81, 82].

4. The Th17-type cells are a subset of $\mathrm{T}$ helper cells so named because of production of the cytokine IL-17. They exert protective effects on the gastrointestinal mucosal barrier function [83]. There is general agreement that Th17-type lymphocytes are protective against extracellular bacterial and fungal infections $[84,85]$. The decrease of Th17 cells population contributes to immunoparalysis [86].

It is widely accepted that the development of a successful immune response requires the balance between Th1 and Th2 helper cells. In the early stage of sepsis and trauma, a phenotypic Th1-type cells profile predominates with IFY production which activates the bactericidal action of macrophages and induces $\mathrm{B}$ cell production of opsonizing and complement-fixing antibodies. Conversely, later (chronic) stages are characterized by a shift from the Th1-type profile into a predominantly Th2-type response leading to immunoparalysis, reduced antigen recognition and cellular anergy (see below) [87]. Other more complex anti-inflammatory actions include the decreased production of monocytederived cytokines by reduced transcriptional factors (NF$\mathrm{kB})$ for the encoding genes [88]. Also, the reduced expression of membrane surface receptor CD14 on monocytes (LPS-receptor) blunts their pro-inflammatory activity. Also the expression of MHC (major histocompatibility complex) class II molecules HLA-DR (human leukocyte antigen) is downregulated [89] with interference in the elimination of infected cells and maturation of several immune cell lines. These anti-inflammatory effects play an important compensatory role in the development of the counter antiinflammatory response syndrome (CARS). Ideally CARS is

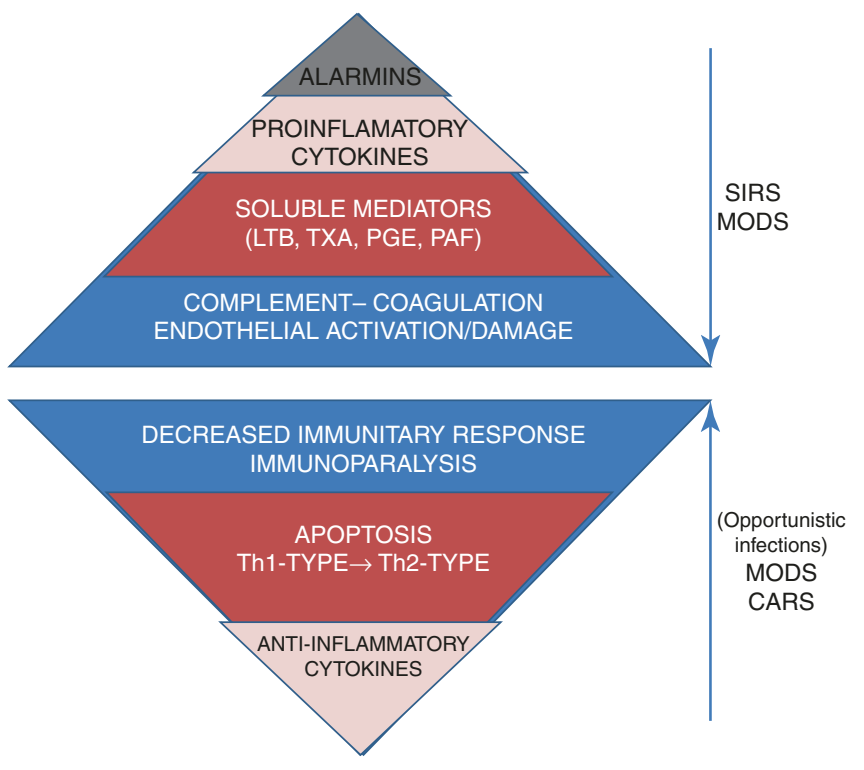

Fig. 2.8 Main steps of SIRS and CARS development with subsequent production of multiple organs dysfunction (MODS)

the physiological response to the risks of tissue damage by uncontrolled inflammation. The main SIRS and CARS events are summarized in Fig. 2.8.

The highly integrated, redundant, and coordinated immune-inflammatory system makes easy its comparison with a great classical orchestra. As a classical orchestra, there are players (neutrophils), soloists (monocytes and macrophages), and the musical score (humoral mediators). This score may be harmoniously classical (locally coordinated inflammatory response) or dissonantly dodecaphonic (SIRS). But who is the conductor?

\subsection{The Endothelium}

This fundamental role is covered by the endothelium. The acquisition that the endothelium orchestrates a complex, often redundant network of the immune-inflammatory players is quite recent. The endothelium is the interface between coagulation and inflammation in sepsis and trauma. Endothelial cells line the vessels in every organ by forming a barrier with organ-specific properties. So the vascular permeability is virtually null in capillaries of the brain and almost complete in the kidney with intermediate levels in the liver, muscle, and lung. The main properties of the endothelium are:

1. Lining the vascular system thus separating the blood from the cells and interstitium

2. Regulating the vascular tone with a net vasodilatory effect 


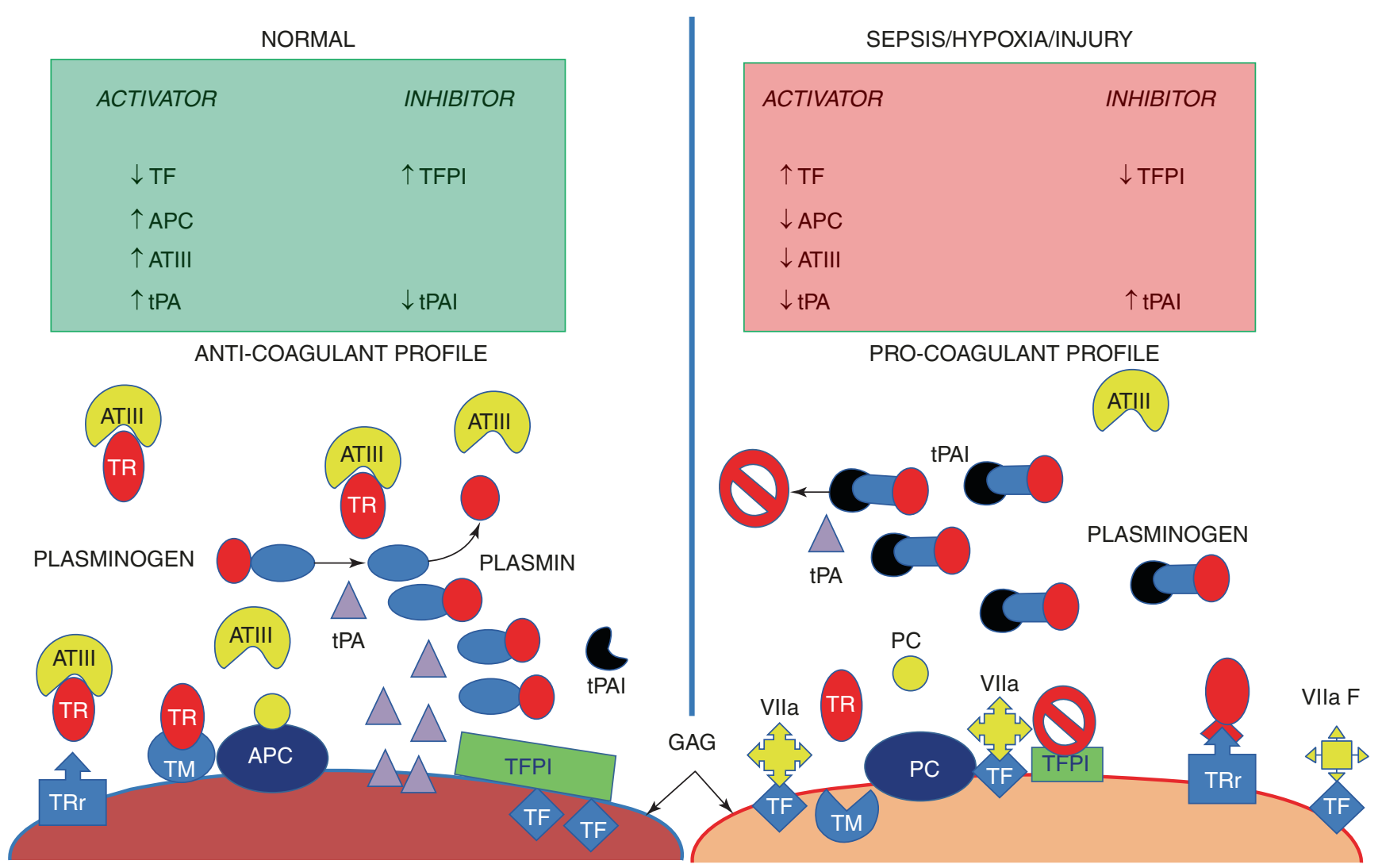

Fig. 2.9 Coagulation profile of endothelial surface during normal (left panel) and activated state (right panel). The anticoagulant profile is normally obtained by inhibition of thrombin (TR) activation of factor $\mathrm{X}$ by thrombomodulin (TM) expression on endothelial surface with formation of the activated protein C complex (APC). Antithrombin III (ATIII) further inhibits Thrombin activity by preventing its binding with receptor (TRr). Also tissue factor (TF) is not expressed on the endothelium, while its main physiological inhibitor, tissue factor pathway inhibitor (TFPI), is normally released by the intact endothelium. Finally the tis-

3. Promoting anticoagulation by anti-thrombotic and profibrinolytic effects

4. Inhibiting the endothelial adhesion of platelets and leukocytes thus keeping the vessel clear

After trauma, hypoxic damage, or sepsis, the injured endothelium becomes prothrombotic and anti-fibrinolytic (Fig. 2.9).

\subsubsection{Endothelial-Mediated Procoagulant State}

The endothelium is involved in all the three major pathogenic pathways of septic and traumatic coagulopathy: tissue factor-mediated thrombin generation, dysfunctional anticoagulation, and fibrinolysis impairment [90]. Moreover, its activation by inflammatory stimulus leads to platelet and sue plasminogen activator (tPA) catalyzes the zymogen plasminogen into plasmin, while tissue plasminogen activator inhibitor type-1 (tPAI1) is reduced. After hypoxia, injury, or sepsis, the damaged endothelium expresses large amounts of TF, while TFPI release is inhibited. Also thrombomodulin receptor is internalized thus reducing APC formation, while decreased ATIII synthesis and degradation by serine protease increases the activity of thrombin. Finally tPAI- 1 synthesis and release are increased thus reducing the formation of plasmin

leukocyte adhesion and inhibition of vasodilation. Endothelial injury can be documented microscopically by a visible change of cell shape or damage and defects of endothelial lining. Indirect evidence of the damaged endothelium is the finding of elevated soluble markers of cell injury notably thrombomodulin, intercellular adhesion molecule, and E-selectin and von Willebrand factor [91, 92]. After endothelial damage, inflammatory fluids and cells can shift from the blood into the interstitial space. Endothelial injury is sustained over time so that its property loss is long-standing [93, 94]. Experimental animal and human studies demonstrated that after injury, the full recovery of endothelial lining occurs within 21 days [93]. The denudation of the vessel wall exposes tissue factor (TF), the principal activator of the extrinsic coagulation pathway with the risk of intravascular coagulation [93, 94]. Normally the outer endothelium expresses various membrane-bound molecules with anticoagulants properties among which are cell surface heparin- 
like molecules [95] and thrombin-binding protein thrombomodulin (TM). Heparin-like molecules are supported by glycosaminoglycans which cover the endothelial surface [90]. They act as cofactors for the antithrombinmediated inhibition of thrombin and activate factor X (StuartPower factor) [95]. TM is the major responsible for thrombin inactivation as when bound to thrombin, forms a potent protein $\mathrm{C}$ (PC) activator complex that equips the endothelium with anticoagulant properties. However, the inflammatory or septic stimuli decrease the anticoagulant properties of the endothelial cells by loss or internalization of TM [96], while the contemporaneous stimulation of the thrombin receptor increases the inflammatory pathways. Finally, the action of neutrophil proteases also contributes to reduced TM expression. Moreover, the release of tissue plasminogen activator (TPa) is decreased, while its main physiological inhibitor, the plasminogen activator inhibitor-1 (PAI-1), increases so that the profibrinolytic properties of the endothelium are diminished. TF is increasingly expressed on both monocyte and macrophage membranes as well as on other cell types, while the function of its main physiological inhibitor, the tissue factor pathway inhibitor (TFPI), is decreased by reduced synthesis of glycosaminoglycans on endothelial surface [97]. In practice, any single procoagulant or profibrinolytic has its physiological inhibitor. Thus, TF is inhibited by TFPI [98], the coagulation system is counteracted by the activated protein C system [99], and tissue plasminogen activator (TPA) is coupled with tissue plasminogen activator inhibitor (TPAi) [100]. The imbalance between these systems results in a net procoagulant state with increased fibrin deposition, microvascular thrombotic occlusion, and risk for tissue ischemia [101]. Direct endothelial damage as occurs after trauma or ischemia-reperfusion injury contributes to activation of coagulation by decreased production of endothelial-derived substances as PGI and NO. The anti-adhesive properties of such molecules reduce leukocytes and platelets aggregation and counteract the procoagulant effectors. Localized coagulation has protective effects in discrete traumatic injuries, but its widespread activation is deleterious to the host with risk for multiple organ dysfunction and death [102, 103].

\subsubsection{Endothelial Pro-adhesive Activation}

Endothelial activation refers to the increased expression of adhesion molecules on endothelium surface. Complementary molecules are also expressed on the outer membrane of neutrophil and monocyte cells [104]. The surface expression, modulation, and activity of these molecules are highly regulated by locally produced cytokines (endothelial and monocyte cells) as the chemokine IL8 or PAF, IL1- $\beta$, and TNF $\alpha$. The first step of the adhesion process consists of a "rolling" of leukocytes on the endothelial surface. This process involves selectins which are molecules expressed on leukocytes (L-selectin), endothelial cells (E-selectin), and platelets (P-selectin). Selectins act as receptors that permit a loose binding with the endothelial surface thus allowing for leukocyte rolling in proximity of opportune signaling molecules expressed on the endothelium. The second step involves the linkage of integrins with receptors of the immunoglobulins superfamily expressed on the endothelium surface. Integrins are a group of three heterodimer proteins expressed on the outer surface of activated leukocytes and collectively termed the CD11/CD18 complex. Adhesion molecules include ICAMs, E-selectins, PECAM (platelet endothelial cell adhesion molecules), and VECAM (vascular endothelial cell adhesion molecules). The final step consists of migration of activated leukocytes to the borders of endothelial cells and interaction with the endothelial-expressed adhesion molecules ICAM, PECAM, E-selectin, and VECAM [105]. Adhesion can occur without intervention of adhesion molecules in the lung and liver. It has been suggested that actincontaining stress fibers increase at the leukocyte periphery, this, in turn, causing decreased PMNs deformability and sequestration into the pulmonary and hepatic capillary beds [106]. The main effects of endothelial cells activation are summarized in Fig. 2.10.

\subsubsection{Dysfunctional Endothelial Permeability}

Thrombin is the main effector of increased endothelial permeability thus reaffirming the bidirectional interplay between the coagulation and the inflammatory cascade (Fig. 2.11). Thrombin can cleave a set of protease-activated receptors (PAR1-4) expressed on the endothelium [90, 107] that induces Rho-dependent cytoskeletal derangement in endothelial cells [108, 109].

PAR1 receptor activates Rho kinase which inhibits the dephosphorylation of myosin light chains (MLC) [110]. Phosphorylated MLC causes the actin-myosin interaction at the cell-to-cell contacts with contraction and rounding of endothelial cells and increased of vascular permeability.

This facilitates the passage of protein molecules and leukocytes from the blood into the interstitial space (Fig. 2.12).

Furthermore, the formation of gaps in the endothelial barrier exposes the proteins of the external coagulation pathway to the abundant TF amount expressed by the basement membrane and vessel adventitia. Clot formation is thus initiated, while collagen fibers from the extracellular matrix prompt $\mathrm{vWf}$ to polymerize and platelets to adhere.

Endothelial dysfunction refers to decreased NO release and reduced expression or synthesis of the constitutive NO synthase enzyme (eNOS). Abnormality of endothelial relaxation properties lasts for many days after the acute insult (endothe- 


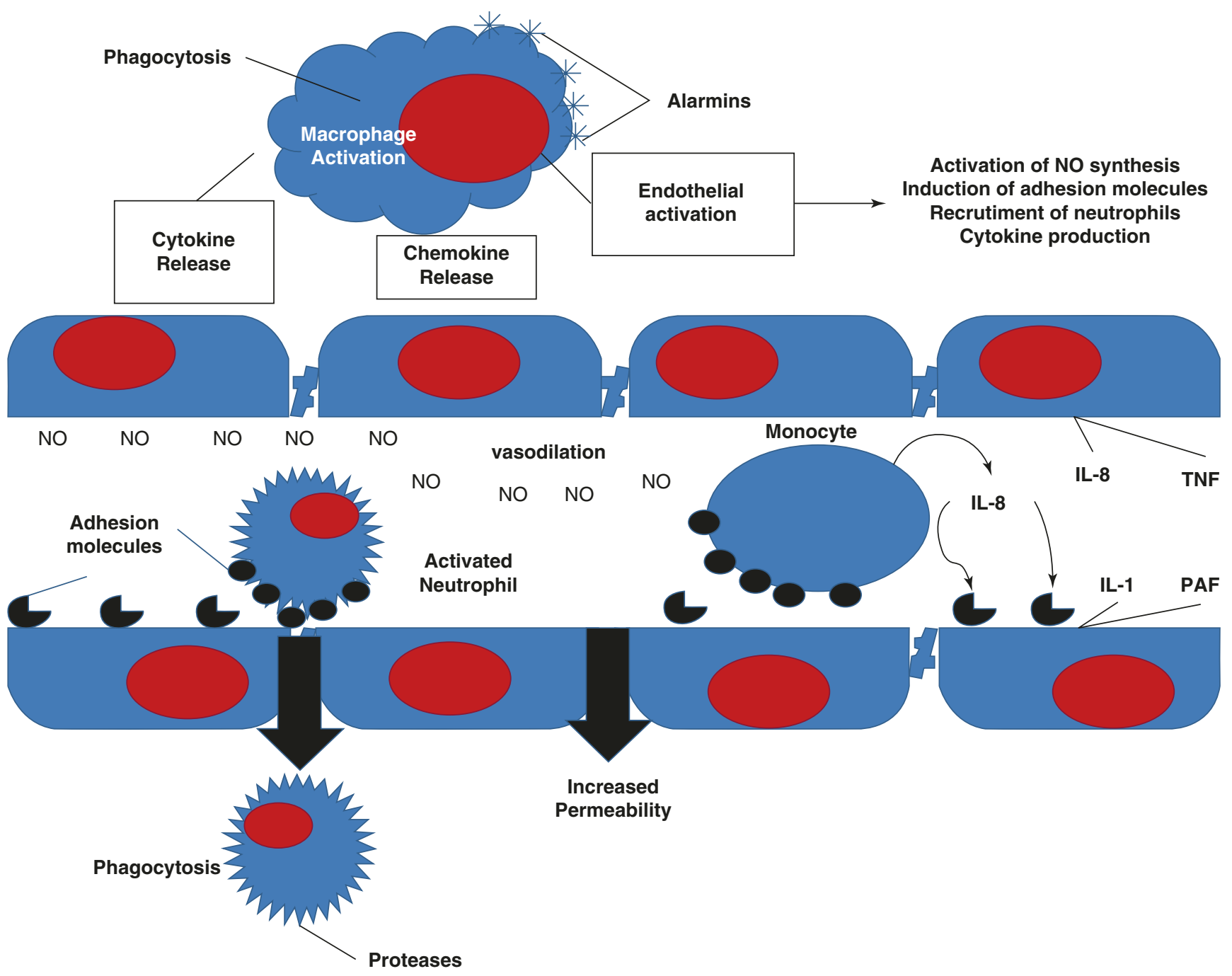

Fig. 2.10 Macrophage secretion of chemokines and cytokines stimulates the synthesis of adhesion molecules on the surface of endothelial cells. Neutrophils are recruited through the vascular wall to the site of inflammation. Monocytes are also stimulated to produce chemokines (mainly IL-8). The activated endothelium maintains inflammation by producing cytokines and other pro-inflammatory mediators. Finally nitric oxide synthesis is induced with vasodilation and loss of autoregulation of microcirculatory blood flow lial stunning) [111]. The impairment of NO and PGI release by endothelial dysfunction have a profound impact upon cellular oxygenation with direct effects on tissues and organs well-being (Fig. 2.10). According to the concept of intrinsic metabolic regulation, oxygen supply and demand are constantly matched. Local vascular relaxation is therefore in dynamic equilibrium with the nervous-mediated vasoconstriction so that capillary blood flow is finely tuned to peripheral requirements. The endothelium plays a crucial role as a sensor of the local blood flow because of functional and structural coupling with the smooth muscle of arterioles and arteries.

Sensing is realized by depolarization/hyperpolarization of the endothelial cells, while communication involves electronic spread via endothelium/muscle cell-cell gap junctions [112]. Therefore, the hyperpolarization of the capillary endo- thelium induces the upstream vasodilation of the feeding arterioles and arteries [113, 114]. When inflammation impairs this finely tuned cell-cell communication, a "malignant intravascular inflammation" ensues [115]. The abnormal vascular reactivity, increased fibrin deposition, and cells adhesion may well account for heterogeneity of intra-organ perfusion and impaired oxygen delivery. The relationship between organ perfusion heterogeneity, impaired organ oxygen supply, and development of metabolic acidosis has been demonstrated in an animal model of endotoxic shock [116]. In an in vivo model of septic shock, a $36 \%$ reduction of perfused capillary density with increased perfusion heterogeneity and mean intercapillaries distance contributed to functional shunting [117] with impaired oxygen extraction after endotoxin challenge or fecal peritonitis $[118,119]$. 
Fig. 2.11 Crosstalk between coagulation, fibrinolysis, and inflammation. (1) After its activation, thrombin stimulates tissue plasminogen activator (tPA) to catalyze the activation of plasmin that in turn stimulates the complement cascade. Thrombin also activates platelets to form arachidonic acid metabolites by membrane-bound phospholipases. (2) Also the Hageman factor (factor XII) stimulates the cleavage of prekallikrein into kallirein and subsequent kinins formation. This effect is potentiated by the positive feedback of plasmin and kallirein with the Hageman factor

Fig. 2.12 Main pathways of increased vascular permeability. Myosin light-chain phosphorylation induces the reorganization of the actin cytoskeleton with acton-non-muscle-myosin interaction and subsequent loss of tight junctions and adherence junction stability
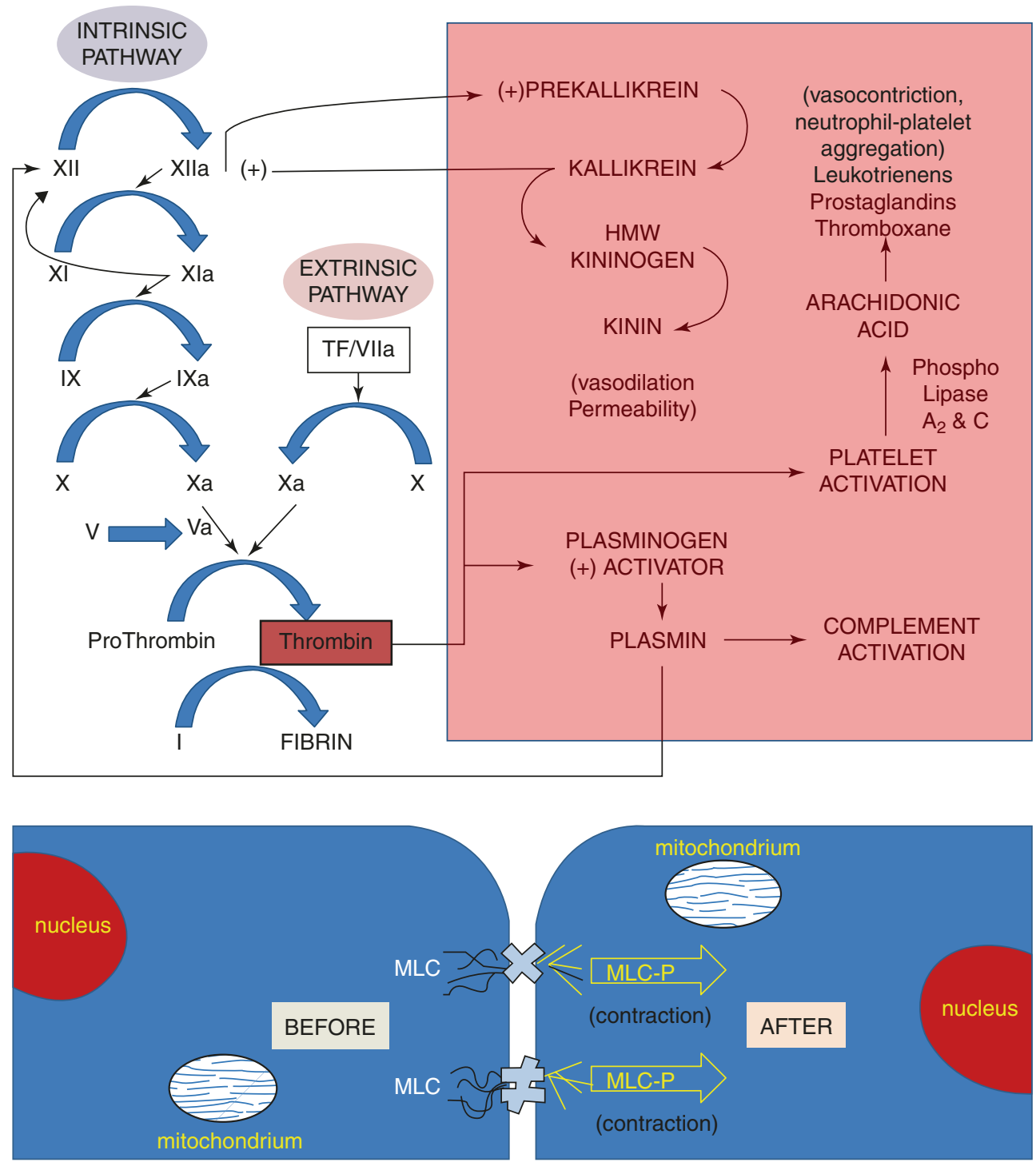

HISTAMINE

THROMBIN

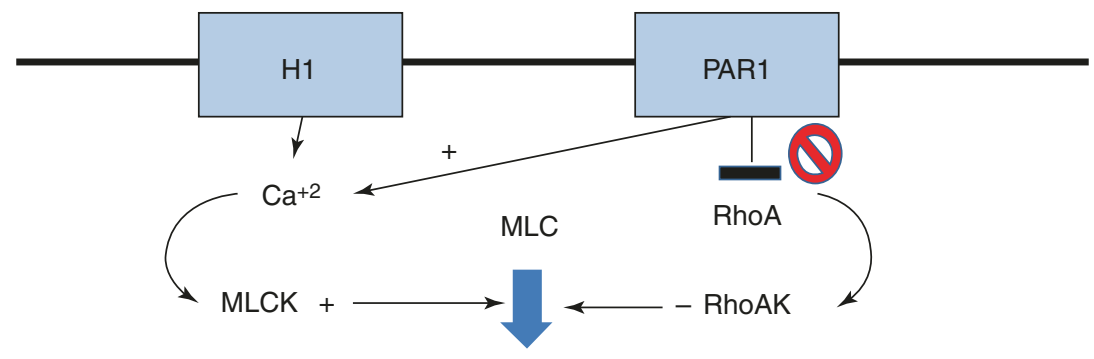

MLC-P

CONTRACTION

\subsection{The Monocyte and Macrophage Cell}

The other fundamental player of the systemic immuneinflammatory activation after trauma and ischemiareperfusion or sepsis is the monocyte/macrophage cell. Monocytes are the circulating form of resident macrophages and dendritic cells. Resident macrophages can be found in the liver (Kupffer cells), lung (alveolar macrophages), lymphoid tissue (spleen and lymph nodes), and kidney (intra-glomerular mesangial macrophages). All these cells are very active in the synthesis of cytokines and removal of particulate antigens. In addition, they play a central role in antigen presentation to the 
innate Th1-type cells. APCs are fundamental for the eradication of pathogens, foreign antigens, or autologous cellular debris. Their key functions include the recognition, uptake, and killing of invading organisms. Tissue macrophages are initially activated after tissue injury by ischemic necrosis of mesenchymal cells in an IL1- $\alpha$-dependent process. After the necrotic insult IL1- $\alpha$ is released from the dying cells with subsequent binding to the IL-1 macrophage surface receptors. IL1- $\alpha$ activates the assembly of inflammasome within the macrophage cytosol. Inflammasomes are multiprotein cytoplasmic complex that cooperate with the Toll-like receptors to respond to various insults by processing cytokines and promoting the inflammatory response. In the presence of pathogenic stimuli (e.g., alarmins), the inflammasome opens up so triggering the conversion of immature pro-inflammatory cytokines (e.g., IL1- $\beta$ ) into mature forms and activating proapoptotic enzymes (e.g., caspases). Thereafter, the extracellular IL1- $\beta$ secretion and upregulation of IL1- $\beta$-induced chemokines, together with the increased expression of adhesion molecules, and cytokines secretion on the nearby endothelium [120, 121] allow for recruitment of circulating neutrophils and monocyte. NO synthesis is activated with resulting vasodilation, opening of endothelial gaps, and loosening of endothelial barrier properties [122] (Fig. 2.8). Monocytes and macrophages are also pivotal cells for the interaction between myeloid and endothelial cells. After the expression of chemoattractant molecules (IL8, monocyte chemoattractant protein-1 MCP-1, or macrophage inhibitory protein-1 MIP-1), the endothelium attracts monocytes to the inflammatory focus where they migrate into the tissue and become macrophages. Finally, the activated monocytes express large amounts of TF to propagate the procoagulant activity. After major uncomplicated trauma, the ability of APCs to express MHCII surface antigens is reduced [122] and returns to normal within a week [123]. After severe injuries, the APCs show a continuously decreased function. This deactivation leads to reduced expression of MHCII surface antigens and decreased ability to secrete cytokines which result into the increased susceptibility to infections [124].

\subsection{Apoptosis}

Many research findings have focused on the existence of premature programmed cell death (apoptosis) after injury, ischemia-reperfusion, and sepsis [125, 126]. Although apoptosis is an adaptive mechanism in several tissue and organs, namely, the lymphoid tissue and gut, its role seems deleterious in acute inflammatory states. Several studies suggest that the programmed cell death contributes to the derangement of cellular homeostasis in parenchymal (lung endothelial cells, kidney tubular cells, and skeletal muscle cells) and lymphoid organs with increased risk for sepsis and development of

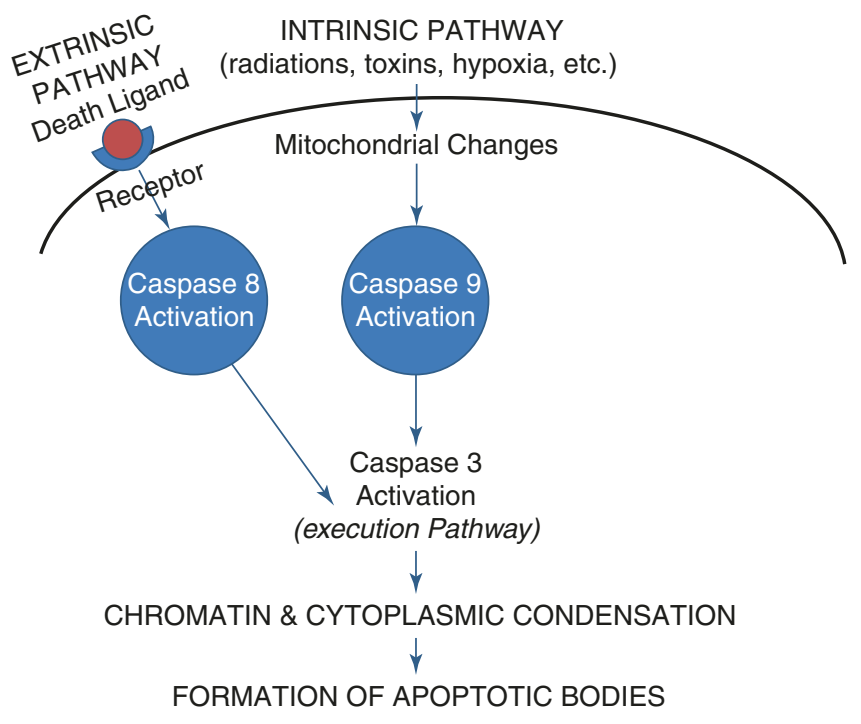

Fig. 2.13 The two main pathways of apoptosis are extrinsic and intrinsic pathway. Each requires specific triggering signals and activates its own initiator caspase which in turn activate the executioner caspase-3. The execution pathway includes cell shrinkage, chromatin condensation, cytoplasmic blebbing, and formation of apoptotic bodies. Finally phagocytosis of apoptotic bodies is performed by adjacent parenchymal cells or macrophages

multiple organ dysfunction [87]. Accelerated apoptosis induces lymphocytopenia [127] and decreased monocyte survival as reflected by loss of monocyte CD14 expression (co-receptor for the detection of bacterial lipopolysaccharideLPS) [82]. Autoactivation of cytosolic and mitochondrial caspases are the two major pathways involved in apoptosis [128] (Fig. 2.13). Briefly, the extrinsic pathways activate caspases via binding to members of the TNF-receptor superfamily, while the mitochondrial induced pathway requires the emission of cytochrome c, otherwise essential for mitochondrial survival, into the cytosol with subsequent caspases activation [129]. Caspases are a family of proteolytic enzymes synthesized as inactive zymogens and activated by appropriate stimuli to express a death effector domain [130]. Apoptosis is a series of coordinated processes [131] that lead to DNA fragmentation, chromatin condensation, and blebs formation in the plasma membranes. Most important this controlled form of cellular degradation carries out with minimal effects on surrounding tissues. Therefore, apoptosis in a crucial physiological process during fetal development and throughout life as it maintains the normal development and regulation of cellular proliferation.

For example, during organ development apoptosis eliminates those cells that are no longer necessary. It has been estimated that without apoptosis, about 2 tons of bone marrow and lymphoid tissue would accumulate in the body [132]! Conversely accelerated apoptosis of lymphocytes is as detrimental as delayed apoptosis in neutrophils. Neutrophil cells are constitutively apoptotic as this ensures a tight con- 
trol of the inflammatory response, but upon delayed apoptotic stimuli (cytokines), neutrophils become persistently activated and contributes to extensive organ damage by continuous release of toxic products (protease enzymes and reactive oxygen species) [133].

\subsection{Immunoparalysis and Chronic Inflammatory States}

Apoptosis causes a profound depression of immune functions with immunoparalysis and depletion of several immune cells including helper $\left(\mathrm{CD}^{+}\right)$and suppressor $\left(\mathrm{CD} 8^{+}\right) \mathrm{T}$ cells, B lymphocytes, and APCs (antigen presenting cells) [134]. Postmortem studies have confirmed immune cells apoptosis in all age groups [134, 135]. It can be speculated that apoptosis of gut-associated lymphoid tissue (GALT) [136] may be involved in bacterial translocation (see below). Several findings support the current view of immunoparalysis as a dominant feature of patients surviving the early hyperinflammatory phase. Although focal regions of inflammation ischemia and necrosis undoubtedly occur and contribute to the development of multiple organ dysfunction, death is the consequence of failure to control the primary infection or the development of new hospital-acquired infections often with opportunistic pathogens. This does not necessarily mean that infection is the main responsible for the patient's death and in fact many postmortem results are inconclusive. However, the severe decrease of innate immune function and the widespread hibernation of nonimmune cell type (cellular hibernation response) $[137,138]$ make apoptosis a primary mechanism for multiple organ dysfunction and ultimately death. Interestingly cancer and sepsis show similar immune defects [139], and increased survival after improving host immunity in cancer patients is encouraging to the field of sepsis. The most frequent manifestations of immunoparalysis include profound and persistent lymphopenia, loss of delayed type 4 hypersensitivity reaction [140], reactivation of latent viruses infections (herpes simplex virus and cytomegalovirus) [141, 142], and infection by low-virulent pathogens (e.g., Stenotrophomonas spp., Candida spp., Acinetobacter spp.) $[143,144]$. Decreased pro-inflammatory cytokines production including IFY, TNF, and IL-2, increased IL-10 and other anti-inflammatory cytokines, decreased monocyte/macrophage and dendritic cells function with increased expression of apoptotic surface markers, and decreased cell survival are the hallmarks of immunoparalysis. Dendritic cells and monocytes play a pivotal role in the development of decreased immune function. Their reduced survival (apoptosis susceptibility) and function abnormalities (reduced HLA-DR expression and increased production of IL-10) induces T helper cell anergy and Treg cell proliferation. The reduced capacity of monocytes to release pro-inflammatory cytokines (e.g., TNF,
IL-1, IL-6, IL-12), whereas the release of anti-inflammatory mediators (e.g., IL-10, IL-1RA) is not impaired or even enhanced [145] suggest for cellular reprogramming toward the anti-inflammatory pathway [146]. Monocyte dysfunction is known as endotoxin tolerance that is reduced cellular response to an endotoxin challenge. The main consequence of endotoxin tolerance is the increased susceptibility to nosocomial infections and death. Decreased immune T-cell function and T-cell exhaustion are the other leading causes of immunoparalysis.

1. The high antigenic load and the elevated pro- and antiinflammatory cytokine profile of the early phase of trauma and sepsis are ideal for the development T-cell exhaustion. Phenotypic features of exhausted $\mathrm{T}$ cells are a decreased production of pro-inflammatory cytokines, mainly IFY and TNF, decreased cellular proliferation and cytotoxic function by excessive expression of PD-1 inducible co-stimulatory molecule and programmed cell death ligand PDL-1, and decreased expression of the IL-7 receptor [148]. IL-7 is a multipotential cytokine that acts to reverse immunosuppression by multiple mechanisms. It has shown to induce the two- to threefold increase of both naïve (Th0-type) and CD4/CD8 cells in cancer [149] and HIV patients [150] so reversing their major pathological abnormality, i.e., profound lymphopenia. Other effects include blockade of apoptosis [151], reversal of T-cell exhaustion [152], increased IFY [152] production leading to macrophage activation, and increased adhesion molecules expression on activated T lymphocytes [153].

The decrease of Th1-type, Th2-type [86, 154-156], and Th17-type cells $[86,157]$ with maintenance of the number of Treg cells leads to the relative increase of regulatory functions and downregulation of effector T-cell response $[86,157]$. The reduction of Th17-type cells contributes to the increased susceptibility to fungal infection due to their important role in protecting against extracellular bacterial and fungal invasion [158]. The relative increase of Treg cells is deleterious as being is associated with decreased effector T-cell proliferation and function. Their increased resistance to apoptosis with respect to the other T-cell type is probably responsible for their increased proportion [159, 160]. Treg cells can also suppress innate immune cells thus inhibiting myeloid-derived cell function [161]. Therefore, increased Treg cells impair the immune function by acting both on innate and adaptive immunity. Neutrophils, NK cells, and $\Upsilon \delta \mathrm{T}$ cells are other effectors whose function is decreased or impaired during immunoparalysis.

2. Briefly circulating neutrophils are markedly increased during the hyperinflammatory phase due to delayed apoptosis and release of immature cellular forms [162, 163]. Loss of chemotactic activity is their most frequently encountered dysfunction $[164,165]$. A subset of 
neutrophils with suppressive properties similar to the myeloid-derived suppressor cells (MDSCs) contributes to the development of immunoparalysis by production of large amounts of IL-10 [166] and interference in proliferation and function of effector T cells [167]. MDSCs are a heterogeneous group of myeloid cells that expand during chronic inflammatory states and cancer as a result of altered hematopoiesis. MDSCs possess strong immunosuppressive properties of both humoral and cellular type [168].

3. NK cells are markedly reduced both in peripheral blood and tissues where they are most abundant [169]. Impaired IFY by NK cells increases the host susceptibility to viral infections and reactivation of latent viruses, notably herpes simplex and cytomegalovirus [141, 142].

4. $\Upsilon \delta \mathrm{T}$ cells are a subset of lymphocytes that possess functions common to the innate and adaptive immune systems. They are particularly abundant in the intestinal mucosa with innate-like defense mechanism (IFY and IL-17 cytokines production). Intestinal $\Upsilon \delta \mathrm{T}$ cells are a first-line defense against infections [170], and their decreased number exposes to the risk of microbial invasion of the blood and peritoneal cavity.

The main effects of chronic inflammation upon innate and acquired immune cells are shown in Figs. 2.14 and 2.15.

\subsection{How Multiple Organ Dysfunction (MODS) Develops}

Multiple organ dysfunction syndrome (MODS) is defined as "the presence of altered organ function in an acutely ill patient such that homeostasis cannot be maintained without intervention" [2]. The mechanisms implicated in the development of MODS include:

1. Induction of cellular apoptosis

2. Translocation of microbes or microbial cellular debris from the gastrointestinal tract chronic sepsis (inflammation) on innate immune cells. Sepsis rapidly triggers dendritic cells, monocytes, and natural killer (NK) cells, while neutrophils apoptosis is contemporarily delayed.

Large amount of released (neutrophils), while the decreased HLA-DR expression (monocytes and dendritic cells) impairs the optimal killing of bacteria
Fig. 2.14 Main effects of extensive apoptosis in immunosuppressive IL-10 are

EFFECTS of PROLONGED SEPSIS on the INNATE IMMUNE SYSTEM

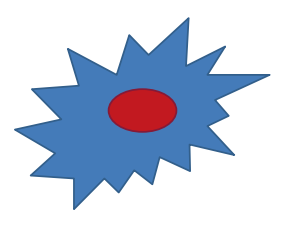

DENDRITIC CELL

\begin{tabular}{|l|}
$\uparrow$ Apoptosis \\
$\downarrow$ Antigen \\
presentation \\
to T \& B cells \\
$\downarrow$ Cytokines \\
secretion. \\
\hline
\end{tabular}

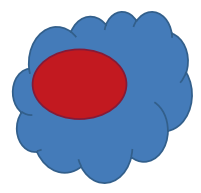

MACROPHAGE

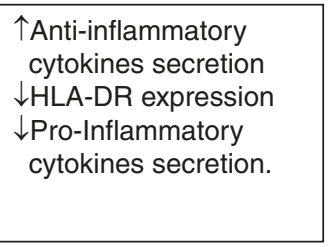

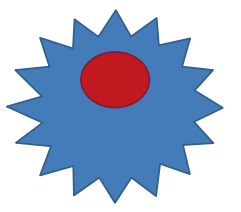

NEUTROPHIL

$\uparrow$ Release of immature
neutrophils
$\downarrow$ Apoptosis
$\downarrow$ Reactive $\mathrm{O}_{2}$
species \& NO release
$\downarrow$ Expression of
adhesion molecules
$\uparrow I \mathrm{IL}-10$ secretion

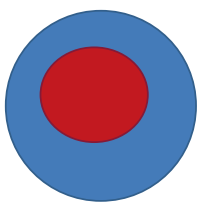

NK CELL
Fig. 2.15 Main effects of chronic sepsis (inflammation) on acquired immune cells. Lymphocytopenia results from massive loss of $\mathrm{T}$ helper and $\mathrm{T}$ suppressor lymphocytes. T regulatory cells are more resistant to apoptosis so that an immunosuppressive phenotype results. Surviving T cells shift from a proinflammatory Th-1 cell-type to an anti-inflammatory Th-2 cell-type profile

\section{EFFECTS of PROLONGED SEPSIS on the ACQUIRED IMMUNE SYSTEM}

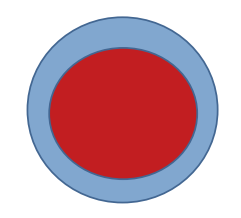

CD4+ T-cell

\begin{tabular}{|l|}
\hline$\uparrow$ Apoptosis \\
$\uparrow \mathrm{T}_{\mathrm{H}} 2$ cell \\
polarization \\
to $\mathrm{T}$ \& B cells \\
$\downarrow$ Adhesion \\
expression \\
molecules.
\end{tabular}

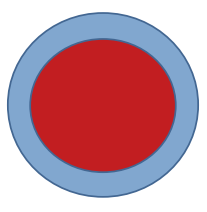

CD8+ T-cell

$\uparrow$ Anti-inflammatory cytokines secretion $\downarrow$ cytotoxic function $\downarrow$ cytokines secretion.

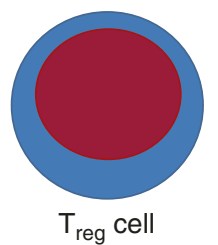

$\uparrow$ Resistance to apoptosis $\uparrow$ suppression

T-cells activities

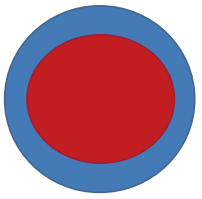

B CELL

$\uparrow$ Apoptosis $\downarrow$ Ag-specific Antibodies production. 
3. Immune system dysregulation

4. Mitochondrial dysfunction

Although the above mechanisms can interact in a variety of ways and combinations, immune system dysregulation and mitochondrial dysfunction seem to play a prevalent role. As detailed above, the immune system dysregulation is the imbalance between pro-inflammatory and anti-inflammatory mechanisms. CARS is a coordinated anti-inflammatory response to severe inflammatory stimuli that allows for the maintenance of immune system homeostasis. The "purpose" of CARS is to limit the noxious effects of SIRS while not interfering with pathogen elimination or healing of the injured tissue. However, CARS may be dangerous when its effects lead to a condition known as "immunoparalysis" with an increased risk of nosocomial sepsis and septic shock. Mitochondrial dysfunction with its hypoxic cellular implications is also important in the pathogenesis of MODS. PMNs production of reactive oxygen species (superoxide and peroxynitrite) and inflammatory cytokines induces oxidative stress that leads to uncoupling of oxidative phosphorylation. The derangement in cellular energy metabolism is known as cytophathic hypoxia, a functional concept that points out the imbalance between adequate oxygen delivery and poor oxygen utilization at the mitochondrial level. When cytophathic hypoxia develops, the result is cellular dysfunction and death. Although "bad" from a clinical point of view, cytophathic hypoxia may be a cellular adaptive response [171] as it can be viewed as a cellular hibernation-like state. However, if this phenomenon occurs for too long, irreversible cellular damage may result [172].

Bacterial translocation is another proposed mechanism for sustained inflammation and development of multiple organ dysfunctions. Although the "sustained-hit model" [173] predicts that the persistent stimulation of natural and acquired immune system by noxious stimuli is responsible for the maintenance of the inflammatory status, recent acquisitions implicate the apoptotic loss of $\delta \Upsilon \mathrm{T}$ cells in the intestinal mucosa [170]. There is good evidence that ischemia-reperfusion injury is the main mechanism for loss of gut barrier function [174]. As oxygenation of the villi is dependent on a counter-current mechanism such that $\mathrm{O}_{2}$ tension at the tip of the villi is lower than that of arterial blood, any decrease in splanchnic blood flow may be associated with bacterial translocation. At this point endotoxin, bacteria, or gut ischemia can stimulate the gut-associated lymphoid tissue to generate an immune-inflammatory response that affects distant organs. Otherwise stated the gut becomes a pro-inflammatory organ, releasing cytokines and other inflammatory mediators which give origin to sepsis and MODS.

According to the point of view of the intensive care medicine, the whole body is constituted by seven physiologically interdependent organ systems: nervous, respiratory, cardiovascular, hepatic biliary, renal, digestive, and coagulation system. Although many of them can be involved, the respiratory and cardiovascular systems are most frequently damaged with acute lung injury (ALI)/acute respiratory distress syndrome (ARDS) and sepsis-induced hypotension being the commonest clinical presentations. It is well established that the number or dysfunctional organs affects the prognosis. Thus the probability to die with only one single dysfunctional organ is fairly less than half with respect to two or more organ dysfunction [175]. Moreover, a multicenter study established that the mortality increases almost linearly from 21.2 to $76.2 \%$ when organ dysfunction increases from 1 to $\geq 4$ organ systems [176]. Mortality is also influenced by comorbidities notably chronic renal failure, diabetes, and cancer [176, 177]. Cumulative comorbidities also increase the risk for the development of MODS with the highest mortality rate [178]. By converse, survivors suffer from a persistent chronic illness that may last for months or even years. This illness is characterized by prolonged ICU stay, slow recovery from organs dysfunction, recurrent infections, progressive or permanent cognitive deficit, and loss of overall sense of well-being and function $[179,180]$. So the duration of healthy life expectancy is reduced although the patient's overall life span is intact.

The common pathophysiological denominator of MODS is the loss of cell membrane barrier function. This finding is strikingly evident from the autopsies of patients who die as a result of multiple organs dysfunction syndrome. Despite the clinical evidence of acute myocardial dysfunction, progressive cholestatic jaundice, continuing impairment of renal function, and similar dysfunction of other organ systems, the histopathological findings are remarkably normal or limited to mild tissue edema. Therefore, the preserved organ morphology is strikingly in contrast with the impairment of organ function. The loss of cellular and tissue (endothelial) barrier function seems the cornerstone for this sort of hibernation that prevents the multiplicity of organ expression, variability, and communication. The commonest clinical presentations of single organ system dysfunctions are shown below.

\subsubsection{Nervous System}

Recent acquisitions indicate that the brain is often involved in sepsis and MODS as it is one target of SIRS either by direct activation of resident pro-inflammatory cells (neuroglia) or by mediators generated elsewhere (complement, cytokines). Although the CNS is considered an immuneprotected organ due to the blood-brain barrier, the abundance of glial cells with their signaling receptors makes the brain one of the preferred target for organ system dysfunction. 
Therefore, the local inflammatory reaction that follows traumatic or hypoxic (e.g., post-cardiac arrest) brain damage can spread outside the CNS thus exacerbating SIRS. Conversely, the circulating cytokines and other inflammatory mediators may increase the permeability of the blood-brain barrier thus causing brain damage [181]. Cytokines activate monocytes to transform into glial cells (equivalent to resident macrophages in extra-cerebral tissues) so that inflammation continues in the nervous tissue [182]. Circulating cytokines also can stimulate the afferent fibers of the vagus nerve that activate the central nervous system. After stimulation of vagus nerve endings, cerebral endothelial cells are activated resulting in the breakdown of the blood-brain barrier [183, 184]. The activation of cerebral endothelium also induces microvascular dysfunction, loss of cerebral vascular tone (autoregulation), and coagulopathy (microthrombi deposition) [185]. Receptors for the commonest cytokines have been found in the hippocampus, one of the most involved regions for mnemonic elaboration and neuroplasticity [181]. Chronic inflammation of the hippocampus can lead to irreversible cognitive decline, especially in the elderly. Histopathologic lesions of the brain in sepsis include cerebral edema, infarct and ischemic lesions, and microabscesses [185]. Sepsisassociated encephalopathy has been reported in $23 \%$ of people in the ICU [186]. However, the true incidence is difficult to estimate because of lack of clear definition and subjective nature of its assessment. Moreover, sedative drugs may blunt the symptoms thus making the diagnosis difficult. Symptoms include changes in consciousness, awareness, cognition, and behavior. Symptoms seem correlated with the global severity of illness as assessed by the Acute Physiology and Chronic Health Evaluation II score (APACHE II score).

\subsubsection{Respiratory System}

It is by far the commonest organ system involved. ALI and ARDS are the two clinical manifestations of respiratory dysfunction. ALI is defined as the presence of bilateral pulmonary infiltrates on chest radiograph and arterial hypoxemia $\left(\mathrm{PaO}_{2} / \mathrm{FiO}_{2}<300\right)$. If the $\mathrm{PaO}_{2} / \mathrm{FiO}_{2}$ drops below 200, the condition is classified as ARDS [187]. ARDS can originate from two distinct pathways:

1. Direct pulmonary damage as occurs after trauma, infection, aspiration, or inhalation injury

2. Indirect damage as occurs with sepsis, pancreatitis, extrapulmonary trauma and burns, blood transfusions, and fat embolism [188, 189]

Respiratory dysfunction span from extremely severe forms requiring immediate tracheal intubation, mechanical ventilation, and paralysis to milder forms with mild hypoxia and tachypnea. The lung is the most frequent organ involved in sepsis and trauma probably because it is the single organ with the largest vascular bed and it harbors one of the largest populations of resident macrophages. ARDS is characterized by neutrophil infiltration, alveolar-capillary barrier disruption, pulmonary vascular leakage, and edema. In most severe forms the alveoli contain eosinophilic protein-rich exudate with presence of hyaline membrane [190]. Electron microscopic examination reveals extensive damage to type I alveolar pneumocytes with cellular swelling and blebbing of the plasma membranes [190]. Pulmonary edema and absorption atelectasis decrease the pulmonary volume with the occurrence of refractory hypoxia by increased pulmonary shunt. Moreover, the widespread deposition of microthrombi and hypoxic pulmonary vasoconstriction impose a pressure overload upon the right ventricle with myocardial dysfunction and failure. The initial clinical presentation is often subtle with tachypnea, dyspnea, dry cough, and agitation. Hypoxia with hypocapnia is the most prominent laboratory feature. The magnitude of hypoxia is often unexplained by the mild or absent roentgenographic signs. CT scan reveals diffuse but nonuniform ground-glass consolidations often with a non-conformal gravitational distribution [191]. In more severe forms, multiple patchy areas of lung consolidation coalesce in massive airspace consolidation [191]. Characteristically the distribution is uniform and affects all lung zones extending to the extreme periphery of the lung fields. Hypoxia and interstitial/alveolar edema stimulate the carotid body chemoreceptors and intraparenchymal lung mechanoreceptors to hyperventilate with decreased arterial carbon dioxide tension. In the latest phases, normocapnia ensues mainly as result of increased respiratory work due to alveolar collapse, decreased pulmonary volume, and respiratory compliance. The mechanical disadvantage of decreased pulmonary compliance causes the abnormal increase of trans-pulmonary pressure (the pressure across the alveoli) that is the driving force for pulmonary expansion. The shear stress upon the delicate alveolar and interstitial structure causes further inflammation as a vicious cycle ensue with endothelial activation and worsening of pulmonary function that influences each other. Mortality from ARDS ranges from 15 to $80 \%$ [189, 192] with average values of about $30 \%$ according to most recent ventilatory strategies [193].

\subsubsection{Cardiovascular Dysfunction}

It is one of the commonest organ dysfunction of septic and/ or traumatic origin. Some studies report an incidence of up to $66 \%[194,195]$ with a mortality rate as high as $70 \%[195$, 196]. The cardiovascular dysfunction has long been recognized as a consequence of the generalized inflammatory reaction [197]. Its most prominent clinical features are (1) 
myocardial dysfunction with biventricular dilation and reduced ejection fraction [198] and (2) arterial hypotension despite fluid volume infusion and decreased response to vasoactive drugs. It generally accepted that the decreased cardiac function is the product of circulating myocardial depressant factors (endotoxin, IL1 $\beta$, TNF $\alpha$, IL6, PAF, and others) and mitochondrial damage [199-201]. Some experimental evidence indicates that endotoxin acts by inducing an inflammatory response through heart tissue macrophage, mast cells, and infiltrating blood leukocytes. The clinical picture includes the following: arterial hypotension, mental impairment, warm and dry skin, oliguria, elevated arterial blood lactates, and higher than normal mixed or central venous saturation. The hemodynamic pattern shows a high cardiac output and decreased peripheral vascular resistance $[202,203]$. The picture of low cardiac output state (pale and wet skin, oliguria, and hypotension) is rarely seen and indicates a more severe form of cardiac depression [202, 203]. When examined in detail, the cardiac function appears depressed as, despite the high output state, the ejected volume is lower than normal (reduced stroke volume), the ventricle is dilated (increased diastolic volume), and its contractile state is impaired with reduced ejection fraction (increased end-systolic volume). These changes are often masked by the decreased peripheral vascular resistance. The reduced afterload allows for the maintenance of a high output state as the dysfunctional ventricle pump blood against a dilated arterial system. When the ventricular dysfunction is severe, the clinical picture resembles that of cardiogenic shock with low cardiac output, high arterial lactates, and intense peripheral vasoconstriction. Several studies have shown that cardiac dysfunction is biventricular in origin and that is potentially reversible by $7-10$ days [204].

The other essential feature of cardiovascular dysfunction is arterial hypotension by decreased peripheral arterial resistance. Because a major fraction of peripheral vascular resistance is located in peripheral arteries, this segment is designated as the resistance vessels. Resistance vessels control the blood flow to organs, and it is under the control of either intrinsic (e.g., metabolic) or extrinsic (e.g., neural and humoral) factors. Intrinsic regulation plays a fundamental role in pressure-flow autoregulation (ability of an organ to keep constant the blood flow despite fluctuations in arterial pressure), reactive hyperemia (ability to increase the blood flow after relief of a vascular obstruction), and functional hyperemia (ability to cope the organ blood flow in accordance with local metabolic needs) [205, 206]. In sepsis, intrinsic regulation is compromised in all the vascular beds with the exception of the cerebral vasculature [207, 208]. This can explain the mismatch between whole oxygen supply and metabolic demands of septic shock. The increased cardiac output does not cope with the cellular energy requirements so that hypoxia and increased acid production develop.
By converse, the extrinsic regulation of resistance vessels is responsible for maintenance of arterial pressure and blood flow to the whole organs. During sepsis and after trauma or ischemia-reperfusion injury, a marked hypo-responsiveness to vasopressor agents is a frequent finding with development of arterial hypotension and tissue hypoperfusion. It is generally accepted that the decreased responsiveness to vasoconstrictor stimuli is consequent to increased production of endothelial nitric oxide (NO) by the induced nitric oxide synthase (iNOS) [209]. In normal arterioles, a small amount of NO is produced by endothelial NOS (eNOS) as maintenance of cardiovascular homeostasis [209]. However, cytokines and endotoxins induce iNOS to produce large quantities of NO [209, 210]. Although iNOS induction can be viewed as an adaptive response to noxious stimuli, the resulting hypotension by massive NO production is deleterious for organs and tissues. Also, there is some evidence that vascular smooth muscle can be another relevant source of NO production. In smooth muscle, neural NOS (nNOS) is upregulated thus contributing to NO generation in septic animals [211]. Another factor implicated in arteriolar hypo-responsiveness may be the complex of morphological alterations of the endothelial lining of the arterioles. Experimental studies show that the endotoxin challenge results into endothelium disruption with cell swelling, pseudopod formation, and frank denudation of the endothelial lining [212,213]. Finally, the loss of capillary to arteriolar signaling may induce the hypo-responsiveness of arterioles to vasopressor stimuli. In normal conditions, capillaries may regulate the arteriolar tone by the upstream spread of electronic signaling along the endothelium. In sepsis, the cell-to-cell communication is impaired so that the modulation of blood flow delivery to capillaries is severely compromised [214]. Taken all together the above mechanisms may lead to the inappropriate redistribution of blood flow to tissues and organs [215, 216]. Because the arterial control of blood flow is responsible for the convective flux of oxygen to capillaries, the alteration of arterial tone may cause regional hypoxia [215] and ultimately multiple organ dysfunction. Treatment principles of hyperdynamic shock are briefly outlined in Chap. 3 .

\subsubsection{Coagulation Dysfunction}

The coagulation system is designed:

1. To stop active blood loss

2. To seal the site of lesion, thus allowing for pathogens destruction and removal of debris

3. To initiate the healing process

The most severe form of coagulation disorder is the disseminated intravascular coagulation (DIC). This pathophysio- 
logic mechanism results from the imbalance between coagulation and fibrinolysis with upregulation of the procoagulant pathway, downregulation of anticoagulant pathway (namely, ATIII, protein C, and S system), and decreased fibrinolysis. Coagulation is regulated by three main anticoagulant mechanisms: antithrombin, the protein $\mathrm{C}$ system, and the tissue factor pathway inhibitor (TFPI). The loss of physiologic anticoagulation in sepsis results from the action of several humoral (IL1- $\beta$, TNF- $\alpha$, and IL6, C-reactive protein) and cellular (vascular endothelial cells, monocytes, macrophages, and platelet) pro-inflammatory mediators. Furthermore, monocytes and macrophages are the main source of tissue factor (TF) a potent thrombin generator via the VII (extrinsic) pathway. The widespread fibrin deposition causes the formation of microthrombi with diffuse microcirculatory flow disturbance. TF is a membrane-bound protein that possesses the most important procoagulant activity [217]. After its expression on the cellular membranes, it forms complexes with the circulating factor VII of the coagulation cascade (extrinsic pathway) thus activating the formation of thrombin [218]. TF is abundant in the subcutaneous tissue and virtually in all blood-tissue barrier [219]. As seen above, TF is also inducible on monocyte and macrophage surfaces. In meningococcal septicemia, large quantities of TF have been localized in microparticles (MPs) shed from platelets and leukocyte aggregates [220]. After trauma or infection, large amount of TF can be expressed by the denuded endothelium, damaged subcutaneous, and muscular tissues with priming of the coagulation cascade. Similarly, sepsis can induce disseminated intravascular coagulation by cytokines production and monocyte adhesion to the activated endothelium with further TF expression. After thrombin formation, the von Willebrand factor (vWf) is released from the Weibel-Palade bodies of endothelial cells. vWf binds to platelet glycoprotein IIb to stabilize the adhesion of platelets and entrapped white blood cells aggregates to the injured endothelium [221]. Normally vWf multimers are cleaved by the protein complex ADAMTS13, and this process is stimulated under conditions of shear stress. Sepsis is associated with decreased circulating ADAMTS13 levels resulting in increased levels of ultra-large vWf multimers [221]. After adhesion to the endothelium (white thrombus formation), platelets enhances the inflammatory and coagulation cascade by expression of TF on activated monocytes and endothelial cells [222]. Clinical conditions associated with overt DIC are summarized in Table 2.3.

The role of DIC in the pathogenesis of MODS is widely supported by experimental and postmortem findings. Firstly, the demonstration of intravascular thrombi at autopsy appears related to the clinical dysfunction of the organ [223]. Secondly, experimental studies demonstrated the deposition of intravascular and extravascular fibrin in the kidneys, lung, liver, and brain [223]. Finally, clinical studies demonstrated the prognostic importance of DIC as being an independent predictor of death [224].
Table 2.3 Clinical pictures often associated with overt DIC

- Sepsis/severe infection (any microorganism)

- Trauma

- Serine protease activation (e.g., pancreatitis)

- Malignancy (solid or myeloproliferative/lymphoproliferative tumors)

- Obstetrical catastrophes (amniotic fluid embolism, abruptio placentae)

- Vascular abnormalities (aneurysms, giant hematomas)

- Severe hepatic failure

- Toxic reactions (snake venoms, drugs)

- Immunological reactions (transplant rejection and transfusion reactions)

The clinical diagnosis of DIC relies upon the simultaneous presence of:

1. Consumption of coagulation factors (prolonged clotting times)

2. Consumption of coagulation inhibitors (e.g., decreased ATIII activity)

3. Platelets consumption or count of less than $100,000 / \mathrm{mm}^{3}$

4. Presence of fibrin degradation products (increased D-dimer)

5. Presence of a condition known to be associated with DIC

In the past decade, clinical simple scoring systems for DIC were introduced (Table 2.4).

They have individual strengths (JAAM has the highest sensitivity, while ISTH is the most specific) and collective weaknesses (poor diagnostic sensitivity for late-onset DIC) [228]. Fibrinogen levels are not sensitive indicators of DIC as fibrinogen synthesis is increased during SIRS as occurs in the acute phase protein reaction. Finally, the diagnosis of DIC can be difficult in the presence of hepatic dysfunction or portal vein thrombosis as many of diagnostic clues of DIC are present in these pathologic conditions. Coagulation dysfunction affects up to $30 \%$ of patients with sepsis [229], while thrombocytopenia $\left(<10^{5}\right.$ platelets $\left./ \mathrm{mm}^{3}\right)$ occurs in up to $60 \%$ with an inverse relationship between platelet count and severity of disease [230, 231].

\subsubsection{Renal Dysfunction}

Acute kidney injury (AKI) is defined as an absolute increase in serum creatinine of 1.5 -fold from baseline or a urine output $<0.5 \mathrm{~mL} / \mathrm{Kg} / \mathrm{h}$ for $6 \mathrm{~h}$ [232]. Overall AKI frequency was reported over $20 \%$ in a large cohort study of 325,395 patients admitted to ICU with odds of death increasing in parallel with increased severity of acute kidney injury [233]. Crude mortality has been found ranging between 28 and $82 \%$ [234, 235]. 
Table 2.4 Most popular DIC scoring systems

\begin{tabular}{|c|c|c|c|c|c|c|}
\hline & JMHW & & ISTH & & JAAM & \\
\hline $\begin{array}{l}\text { Underlying } \\
\text { disease }\end{array}$ & $\begin{array}{l}\text { Absent } \\
\text { Present }\end{array}$ & $\begin{array}{l}0 \\
1\end{array}$ & Required & & Required & \\
\hline $\begin{array}{l}\text { Clinical } \\
\text { presentation } \\
\text { No Bleeding } \\
\text { Bleeding } \\
\text { No MODS } \\
\text { MODS }\end{array}$ & $\begin{array}{l}0 \\
1^{\mathrm{a}} \\
0 \\
1\end{array}$ & & & $\begin{array}{l}\text { No } \\
\text { SIRS } \\
\text { SIRS }\end{array}$ & $\begin{array}{l}0 \\
1\end{array}$ & \\
\hline $\begin{array}{l}\text { Platelet } \\
\text { count }\end{array}$ & $\begin{array}{l}>120 \\
80-120 \\
50-80 \\
\leq 50\end{array}$ & $\begin{array}{l}0 \\
1^{\mathrm{a}} \\
2^{\mathrm{a}} \\
3^{\mathrm{a}}\end{array}$ & $\begin{array}{l}>100 \\
50-100 \\
<50\end{array}$ & $\begin{array}{l}0 \\
1 \\
2\end{array}$ & $\begin{array}{l}\geq 120 \\
80-120 \text { or } \\
-30 \% \\
\text { reduction in } \\
24 \mathrm{~h} \\
<80 \text { or } \\
-50 \% \\
\text { reduction in } \\
24 \mathrm{~h}\end{array}$ & $\begin{array}{l}0 \\
1 \\
2\end{array}$ \\
\hline$F D P$ & $\begin{array}{l}<10 \\
10-20 \\
20-40 \\
>40\end{array}$ & $\begin{array}{l}0 \\
1 \\
2 \\
3\end{array}$ & & & $\begin{array}{l}<10 \\
10-25 \\
>25\end{array}$ & $\begin{array}{l}0 \\
1 \\
2\end{array}$ \\
\hline $\begin{array}{l}\text { Fibrin- } \\
\text { related } \\
\text { marker (e.g., } \\
\text { soluble fibrin } \\
\text { monomer, } \\
\text { FDP) }\end{array}$ & & & $\begin{array}{l}\text { Normal } \\
\text { Moderate } \\
\text { Strong }\end{array}$ & $\begin{array}{l}0 \\
2 \\
3\end{array}$ & & \\
\hline Fibrinogen & $\begin{array}{l}>1.5 \\
1.0-1.5 \\
\leq 1\end{array}$ & $\begin{array}{l}0 \\
1 \\
2\end{array}$ & $\begin{array}{l}>1.0 \\
<1.0\end{array}$ & $\begin{array}{l}0 \\
1\end{array}$ & & \\
\hline PT ratio & $\begin{array}{l}<1.25 \\
1.25-1.67 \\
\geq 1.67\end{array}$ & $\begin{array}{l}0 \\
1 \\
2\end{array}$ & & & $\begin{array}{l}<1.2 \\
\geq 1.2\end{array}$ & $\begin{array}{l}0 \\
1\end{array}$ \\
\hline $\begin{array}{l}\text { Prolonged } \\
\text { prothrombin } \\
\text { time }\end{array}$ & & & $\begin{array}{l}<3.0 \mathrm{~s} \\
3.0-6.0 \mathrm{~s} \\
>6.0 \mathrm{~s}\end{array}$ & $\begin{array}{l}0 \\
1 \\
2\end{array}$ & & \\
\hline Diagnosis & & $\geq 7$ & & $\geq 5$ & & $\geq 4$ \\
\hline
\end{tabular}

JMHW Japanese Ministry of Health and Welfare [225], ISTH International Society of Thrombosis and Haemostasis [226], JAAM Japanese Association of Acute Medicine [227]

af hematologic malignancy, 0 pts for bleeding and platelets and add 3 pts to the total score

The severity of AKI is classified using the risk, injury, failure, loss and end-stage renal disease (RIFLE) criteria listed in Table 2.5, [236].

Two main pathways are responsible for AKI: one is characterized by acute tubular necrosis, renal hypoperfusion, and ischemia-despite common belief, this form accounts for only $22 \%$ of sepsis-induced AKI [237] —and the second form is specific to MODS, and its predominant mechanism is apoptosis induced by inflammatory cytokines [238]. This pathogenic mechanism is more adherent to the hyperdynamic circulatory state that follows post-traumatic SIRS and sepsis [239]. Experimental studies suggest that the decrease in glomerular filtration rate in AKI is the result of a disproportionate vasodilation of the efferent than the afferent glomerular arterioles [240]. In normal condition, the vascular
Table 2.5 Criteria for acute kidney injury

\begin{tabular}{l|l} 
Risk (R) & $\begin{array}{l}\text { Serum creatinine increased } \geq 1.5 \text { over } \\
\text { baseline }\end{array}$ \\
\hline Injury (I) & $\begin{array}{l}\text { Serum creatinine increased } \geq 2 \text { over } \\
\text { baseline }\end{array}$ \\
\hline Failure (F) & $\begin{array}{l}\text { Serum creatinine increased } \geq 3 \text { over } \\
\text { baseline }\end{array}$ \\
\hline $\begin{array}{l}\text { Loss (L) } \\
\text { End-stage renal disease (E) }\end{array}$ & $\begin{array}{l}\text { Loss of renal function }>4 \text { weeks } \\
\text { Lostion }>3 \text { months }\end{array}$
\end{tabular}

Modified from [236]

tone of afferent and efferent vessels is regulated by humoral intra-glomerular factors (mainly angiotensin, thromboxane A2, and PGI2). The interplay between vasoconstrictor (angiotensin and thromboxane A2) and vasodilator (PGI2) factors causes the tone of efferent vessels to increase with respect to the afferent arterioles. This allows for the glomerular capillary pressure to ensure normal filtration. During SIRS or sepsis, the dilation of the efferent arterioles decreases the glomerular pressure and hence the filtration rate [241]. This pathophysiologic mechanism can explain the positive effects of norepinephrine or vasopressin infusion in patients with SIRS and oliguria. Despite the common belief, norepinephrine and vasopressin have been reported to increase the urinary output in patients with hyperdynamic shock. Their vasoconstrictor effect is probably helpful in restoring the tone of the efferent arteriole with resulting increase of capillary perfusion pressure. In addition to glomerular hemodynamic changes, circulating or locally (mesangial cells) produced TNF $\alpha$ induces tubular cell apoptosis with imbalance in water and electrolytes homeostasis [242]. AKI is an important form of organ dysfunction because of its association with high mortality rates. In a multinational, multicenter study, the prevalence of AKI has been estimated to be 5-6\% of people with only $40 \%$ of them discharged alive [243]. Septic shock is the most common cause of AKI with a prevalence of $65 \%$ [244]. Trauma patients who developed AKI showed $29 \%$ of mortality rate as compared with $9 \%$ of the overall mortality rate [245].

\subsubsection{Hepatic and Gut Dysfunction}

The gut has long been recognized as the "motor" of MODS due to its capability of amplifying the SIRS response during shock and gut hypoperfusion. The incidence of gastrointestinal dysfunction is difficult to estimate due to the subjective nature of diagnosis and the lack of a clear diagnostic definition. Symptoms and signs of intestinal dysfunction include hyporexia, anorexia, inability to tolerate enteral feeding, decreased intestinal motility, and diarrhea often of hemorrhagic type [246, 247]. After a catastrophic hypoperfusion of the gut as occurs with cardiac arrest or severe multiple 
trauma, the normal intestinal flora is destroyed and substituted by an increasing number of pathogens [248]. This phenomenon is detrimental because the normal flora protects against the colonization of microbial pathogens thus preventing bacterial translocation (see above) [249]. However, the change of normal flora together with reduced intestinal motility and disruption of normal gut mucosal barrier increase the risk for bacterial translocation and development of MODS. The loss of mucosal barrier function is the result of endotoxin, inflammatory cytokines, and decreased production of tight junction proteins [250].

Hepatic dysfunction is schematically divided into two clinical forms: hypoxic hepatitis $(\mathrm{HH})$ and jaundice-induced cholestasis (JIC). HH can result from absolute (e.g., cardiogenic) or relative decrease in cardiac output with reduced oxygen supply to the liver. During septic shock, cardiac output and oxygen delivery are increased albeit not enough to cope with the high oxygen requirement of the liver and the inability of cells to extract oxygen [45]. Moreover, the hepatic arterial buffer response and other vascular mechanisms of defense against portal blood flow reduction are impaired [251]. HH is also the product of oxidative stress after ischemia/reperfusion injury and the action of endotoxin and other inflammatory mediators which lead to activation of Kupffer cells and activation and recruitment of leukocytes. The diagnosis of $\mathrm{HH}$ requires:

1. A clinical setting of impaired oxygen delivery (usually due to cardiac and/or respiratory failure)

2. A greater than 20-fold increase in serum aminotransferase activity

3 . The exclusion of other causes of liver cell necrosis $[252,253]$

Another landmark of $\mathrm{HH}$ is the acute drop of prothrombin levels which gives origin to a hemorrhagic syndrome [254]. These acute biochemical changes, especially those reflecting acute liver cells necrosis, decrease rapidly within 2 or 3 days and normalize within approximately 2 weeks. The delayed elevation of serum bilirubin is often seen but without apparent jaundice. Jaundice-induced cholestasis is a more subtle form of hepatic jaundice usually associated with severe infections $[255,256]$. The increase of bilirubin is a late event in these septic patients [257], and histological studies reveal the intrahepatic origin of the cholestasis [258]. The reduction of bile salt excretion in the gut is responsible for the atrophy of the mucosal gut barrier [259] with loss of integrity and increased risk of bacterial translocation. Moreover, the gut is deprived by the bacteriostatic action of bile salts with proliferation of pathogens and increased production of endotoxin [260, 261]. This creates a vicious circle that perpetuates the infection and hence further cholestatic liver damage. The production and transport of bile salts are a complex, highly coordinated, and energy-dependent mechanism. During sepsis many of these mechanisms are impaired because of a lack of energy due to hypoxia or hypoperfusion or both [262]. The major limiting factor for the bile flow at the canalicular level is the ATPdependent bile salt export pump that is severely impaired in the septic liver [262]. The severity of hyperbilirubinemia appears directly related to the severity of impairment in the various steps of bile formation. No specific therapies can be recommended for acute liver dysfunction. The most recommended measures are merely supportive including the normalization of perfusion pressure and restoration of oxygen delivery [263], the maintenance of normal oxygen tension, and serum glucose levels. The early use of enteral nutrition is also helpful in counteracting the atrophy of gut mucosal barrier and reducing the intestinal pathogens [264].

\section{Case Scenario}

A high-impact trauma victim was admitted to ED with head trauma and severe hemorrhagic shock by ruptured spleen and multiple bone fractures. The patient was unconscious; his blood pressure was $85 / 55 \mathrm{mmHg}$ with $135 \mathrm{bpm}$ pulse rate. Metabolic acidosis ( $\mathrm{pH} 7.27$, $\mathrm{PaCO} 232 \mathrm{mmHg}$ ) and hyperlactacidemia $(7.5 \mathrm{mmol} / \mathrm{L})$ were also present. Splenectomy and external fixation of bone fractures were quickly performed. During surgery, the blood pressure remained at about 100/60 with an average $120 \mathrm{bpm}$ pulse rate. Despite several liters of crystalloids and transfusion of blood products (4 PRC and $4 \mathrm{FFP}$ ), an infusion of norepinephrine up to $0.15 \mu \mathrm{g} / \mathrm{Kg} / \mathrm{min}$ was started. At ICU admission, the patient had stable vital signs (AP $115 / 50 \mathrm{mmHg}$ ) a mild tachicardia (HR $115 \mathrm{bpm}$ ), and compensated metabolic acidosis ( $\mathrm{pH} 7.37, \mathrm{PaCO} 230 \mathrm{mmHg}$ ) with elevated arterial blood lactates $(7 \mathrm{mmol} / \mathrm{L})$. After $12 \mathrm{~h}$ from ICU admission, the resuscitation phase appeared complete. At $24 \mathrm{~h}$, fever of $38.8^{\circ} \mathrm{C}$, leukocytosis 21,000 cells $/ \mathrm{mm}^{3}$, respiratory alkalosis, and tachycardia prompted the execution of a total body CT scan.

1. What is the most probable diagnosis?
A. Sepsis
B. SIRS
C. Intra-abdominal abscess
D. Fever of CNS origin

2. Which are the cytokines involved in the onset of fever and leukocytosis?
A. IL-4 and IL-10
B. IL-1 and TNF
C. IL-6 and IL-7
D. None of the above answers 
The CT scan excluded intra-abdominal abscesses and revealed large bilateral psoas muscle and pelvic hematomas. Microbiological cultures from urine, bronchial tube drainage fluids were negative. Within 5 days fever and tachycardia disappeared so that the definitive fixation of bone fractures was scheduled for the following week.

At day 10, a new appearance of fever and leukocytosis occurred.

\section{What is the most probable origin of fever in this} patient?
A. Infection
B. SIRS
C. Drugs-induced fever
D. Fever of unknown origin

The chest roentgenogram showed a right perihilar infiltrate and purulent bronchial secretions. Broad spectrum antibiotics were started, but $24 \mathrm{~h}$ thereafter the patient develops hypotension, oliguria, metabolic acidosis, altered mental status, and decreased platelet count.

\section{What is the most probable cytokines profile?}

A. Increased pro-inflammatory and decreased anti-inflammatory cytokines (SIRS)

B. Predominance of anti-inflammatory upon proinflammatory cytokine profile (CARS)

C. Balanced pro- and anti-inflammatory cytokines profile (MARS)

D. None of the above answers

A multi-sensitive Klebsiella pneumoniae was isolated from blood cultures, and antimicrobial therapy allows for rapid control of the septic source and resolution of the clinical picture. The patient was discharged from intensive care after 15 days and returned at home within 60 days from the hospital admission.

Please see Chap. 58 for the correct answer.

\section{References}

1. Bone RC. Sir Isaac Newton, sepsis, SIRS and CARS. Crit Care Med. 1996;24:1125-8.

2. American College of Chest Physicians/Society of Critical Care Medicine Consensus Conference: definitions for sepsis and organ failure and guidelines for the use of innovative therapies in sepsis. Crit Care Med. 1992;20:864-74.

3. Lord JM, Midwinter MJ, Chen Y, Belli A, Brohi K, Kovacs EJ, Koenderman L, Kubes P, Lilford RJ. The systemic immune response to trauma: an overview of pathophysiology and treatment. Lancet. 2014;384:1455-65.
4. Osuchowski MF, Craciun F, Weixelbaumer KM, Duffy ER, Remick DG. Sepsis chronically in MARS: systemic cytokine responses are always mixed regardless of the outcome, magnitude, or phase of sepsis. J Immunol. 2012;189(9):4648-56.

5. Hotchkiss RS, Karl IE. The pathophysiology and treatment of sepsis. N Engl J Med. 2003;348:138-50.

6. Oberholzer A, Oberholzer C, Moldawer LL. Sepsis syndromes: understanding the role of innate and acquired immunity. Shock. 2001;16:83-96.

7. Hotchkiss RS, Monneret G, Payen D. Immunosuppression in sepsis: a novel understanding of the disorder and new therapeutic approach. Lancet Infect Dis. 2013;13:260-8.

8. Riche FC, Cholley BP, Panis YH, Laisne MJ, Briard CG, Grauler AM, Gueris JL, Valleur PD. Inflammatory cytokine response in patients with septic shock secondary to generalized peritonitis. Crit Care Med. 2000;28:433-7.

9. Brunialti MK, Martins PS, de Carvalho B, Machado FR, Barbosa LM, Salomao R. TLR2, TLR4, CD14, CD11B, and CD11C expressions on monocytes surface and cytokine production in patients with sepsis, severe sepsis and septic shock. Shock. 2006;25:351-7.

10. Iskander KN, Osuchowski MF, Stearns-Kurosawa DJ, Kurosawa S, Stepien D, Valentine C, Remick DG. Sepsis: multiple abnormalities, heterogeneous responses, and evolving understanding. Physiol Rev. 2013;93:1247-88.

11. Osuchowski MF, Welch K, Yang H, Siddiqui J, Remick D. Sepsis: always in MARS. Shock. 2006;25:5.

12. Heidecke CD, Hensler T, Weighardt H, Zantl N, Wagner $H$, Siewert JR, Holzmann B. Selective defects on T lymphocytes function in patients with lethal intraabdominal infection. Am J Surg. 1999;178:288-92.

13. Ploder M, Pelinka L, Schmuckenschlager C, Wessner B, Ankersmit HJ, Fuerst W, Redl H, Roth E, Spittler A. Lipopolysaccharideinduced tumor necrosis factor alpha production and not monocyte human leukocyte antigen-DR expression is correlated with survival in septic trauma patients. Shock. 2006;25:129-34.

14. Cavaillon JM, Adib-Conquy M, Cloez-Tayarani I, Fitting C. Immunodepression in sepsis and SIRS assessed by ex-vivo cytokine production is not a generalized phenomenon: a review. J Endotoxin Res. 2001;7:85-93.

15. Bianchi ME. DAMPs, PAMPs and alarmins: all we need to know about danger. J Leukoc Biol. 2007;81:1-5.

16. Pugin J. How tissue injury alarms the immune system and causes a systemic inflammatory response. Ann Intensive Care. 2012;2:22.

17. Zhang Q, Raoof M, Chen Y, Sumi Y, Sursal T, Junger W, Brohi K, Itagaki K, Hauser CJ. Circulating mitochondrial DAMPSs cause inflammatory response to injury. Nature. 2010;464:104-7.

18. Chen G, Li J, Ochani M, Rendon-Mitchell B, Qiang X, Susarla S, Ulloa L, Yang H, Fan S, Goyert SM, Wang P, Tracey KJ, Sama AE, Wang $\mathrm{H}$. Bacterial endotoxin stimulates macrophages to release HMGB1 partly through CD14- and TNF-dependent mechanisms. J Leukoc Biol. 2004;76:994-1001.

19. Zedler S, Faist E. The impact of endogenous triggers on traumaassociated inflammation. Curr Opin Crit Care. 2006;12:595-601.

20. Manson J, Thiemermann C, Brohi K. Trauma alarmins as activators of damage-induced inflammation. Br J Surg. 2012;99(Suppl 1):12-20.

21. Burk AM, Martin M, Flierl MA, Rittirsch D, Helm M, Lampl L, Bruckner U, Stahl GL, Blom AM, Perl M, Gebhard F, Huber-Lang MS. Early complementopathy after multiple injuries in humans. Shock. 2012;37(4):348-54.

22. Neher MD, Weckbach S, Flierl MA, Huber-Lang MS, Stahel PF. Molecular mechanisms of inflammatory and tissue injury after major trauma-is complement the "bad guy"? J Biomed Sci. 2011;18(1):90.

23. Huber-Lang MS, Kotvun A, Ignatius A. The role of complement in trauma and fracture healing. Semin Immunol. 2013;25:73-8.

24. Harris HE, Raucci A. Alarmin(s) news about danger: workshop on innate danger signals and HMGB1. EMBO Rep. 2006;7:774-8. 
25. Wang H, Vishunabhakat JM, Bloom O, Zhang M, Ombrellino M, Sama A, tracey KJ. Proinflammatory cytokines (tumor necrosis factor and interleukin 1) stimulate release of high mobility group protein-1 by pituicytes. Surgery. 1999;126:389-92.

26. Scaffidi P, Misteli T, Bianchi ME. Release of chromatin protein HMGB1 by necrotic cells triggers inflammation. Nature. 2002;418:191-5.

27. Gardella S, Andrei C, Ferrera D, Lotti LV, Torrisi MR, Bianchi ME, Rubartelli A. The nuclear protein HMGB1 is secreted by monocytes via a non-classical, vesicle-mediated secretory pathway. EMBO Rep. 2002;3:995-1001

28. Andersson U, Wang H, Palmblad K, Aveberger AC, Bloom O, Erlandsson-Harris H, Janson A, Kokkola R, Zhang M, Yang H, Tracey KJ. High mobility group 1 protein (HMG-1) stimulates proinflammatory cytokine synthesis in human monocytes. J Exp Med. 2000;192:565-70.

29. Rouhianen A, Kuja-Panula J, Wilkman E, Pakkanen J, Stenfors J, Touminen RK, Leptanlo M, Carpén O, Parkkinen J, Rauvala $\mathrm{H}$. Regulation of monocyte migration by amphoterin (HMGB1). Blood. 2004;104:1174-82.

30. Roumen RM, Redl H, Schlag G. Inflammatory mediators in relation to the development of multiple organ failure in patients after severe blunt trauma. Crit Care Med. 1995;23:474-80.

31. Rose S, Marzi L. Pathophysiology of polytrauma. Zentralbl Chir. 1996;121(11):896-913.

32. Mollnes TE, Fosse E. The complement system in trauma-related and ischemic tissue damage: a brief review. Shock. 1994;2:301-10.

33. Biffl WL, Moore EE, Moore FA, Carl VS, Kim FJ, Franciose RJ. Interleukin-6 potentiates neutrophil priming with plateletactivating factor. Arch Surg. 1994;129:1131-6.

34. Friese RS, Rehring TF, Wollmering M, Moore EE, Ketch LL, Banerjee A, Harken AH. Trauma primes cells. Shock. 1994;1:388-94.

35. Hietbrink F, Koenderman L, Rijkers G, Leenen L. Trauma: the role of the innate immune system. World J Emerg Surg. 2006;1:15.

36. Partrick DA, Moore FA, Moore EE, Barnett CC Jr, Silliman CC. Neutrophil priming and activation in the pathogenesis of postinjury multiple organ failure. New Horiz. 1996;4:196-210.

37. Alcaide P, Auerbach S, Luscinskas FW. Neutrophil recruitment under shear flow: it's all about endothelial rings and gaps. Microcirculation. 2009;16:43-57.

38. Giannoudis PV, Hildebrand F, Pape HC. Inflammatory serum markers in patients with multiple trauma. Can they predict outcome. J Bone Joint Surg Br. 2004;86(3):313-23.

39. Lenz A, Franklin GA, Cheadle WG. Systemic inflammation after trauma. Injury. 2007;38:1336-45.

40. Zhu J, Yamane H, Paul WE. Differentiation of effector C4 T cell populations. Annu Rev Immunol. 2010;28:445-89.

41. Botha AJ, Moore FA, Moore EE. Postinjury neutrophil priming and activation: an early vulnerable window. Surgery. 1995;118:358-65.

42. DeLong WG Jr, Born CT. Cytokines in patients with polytrauma. Clin Orthop Relat Res. 2004;422:57-65.

43. Grell M, Becke FM, Wajant H, Mannel DN, Scheurich P. TNF receptor type 2 mediates thymocyte proliferation independently of TNF receptor type 1. Eur J Immunol. 1998;28:257-63.

44. Carpentier I, Coonaert B, Beyaert R. Function and regulation of tumor necrosis factor type 2. Curr Med Chem. 2004;11:2205-12.

45. Dinarello CA. Interleukin-1 beta. Crit Care Med. 2005;33:S460-2.

46. Shalaby MR, Waage A, Espevik T. Cytokine regulation of interleukin 6 production by human endothelial cells. Cell Immunol. 1989;121:372-82.

47. Opal SM, DePalo VA. Anti-inflammatory cytokines. Chest. 2000;117:1162-72.

48. Tilg H, Trehu E, Atkins MB, Dinarello CA, Mier JW. Interleukin-6 (IL-6) as an anti-inflammatory cytokine. Induction of circulating
IL-1 receptor antagonist and soluble tumor necrosis factor receptor p55. Blood. 1994;83:113-8.

49. Lin E, Calvano SE, Lowry SF. Inflammatory cytokines and cell response in surgery. Surgery. 2000;127:117-26.

50. Xing Z, Gauldie J. Cox G IL6 is an anti-inflammatory cytokine required for controlling local or systemic acute inflammatory responses. J Clin Invest. 1998;101:311-20.

51. Jekarl DW, Lee SY, Park YJ, Kim Y, Park JH, Wee JH, Choi SP. Procalcitonin as a diagnostic marker and IL-6 as a prognostic marker for sepsis. Diagn Microbiol Infect Dis. 2013;75(4):342-7.

52. Takahashi W, Nakada TA, Yazaki M, Oda S. Interleukin-6 levels act as a diagnostic marker for infection and a prognostic marker in patients with organ dysfunction in the intensive care unit. Shock. 2016;46(3):254-60.

53. Inagaki $T$, Hoshino M, Hayakawa $T$, Ohara $H$, Yamada $T$, Yamada H, Lida M, Nakazawa T, Ogasawara T, Uchida A, Hasegawa C, Miyaji M, Takeuchi T. Interleukin 6 is a useful marker for early prediction of the severity of acute pancreatitis. Pancreas. 1997;14(1):1-8.

54. Keane MP, Strieter RM. Chemokine signaling in inflammation. Crit Care Med. 2000;28:N13-26.

55. Fosse E, Pillgram-Larsen J, Svennevig JL, Nordby C, Skulberg A, Mollnes TE, Abdelnoor M. Complement activation in injured patients occurs immediately and is dependent on the severity of the trauma. Injury. 1998;29(7):509-14.

56. Stahel PF, Morganti-Kossman MC, Kossmann T. The role of the complement system in traumatic brain injury. Brain Res Rev. 1998;27:243-56

57. Buzdon MM, Napolitano LM, Shi HJ, Ceresoli DM, Rauniya R, Bass BL. Femur fracture induces site-specific changes in T-cells immunity. J Surg Res. 1999;82(2):201-8.

58. Weiser MR, William JP, Moore FD Jr, Kobzik L, Ma M, Hechtman HB, Carroll MC. Reperfusion injury of ischemic skeletal muscle is mediated by natural antibody and complement. J Exp Med. 1996;183(5):2343-8.

59. Zhang M, Alicot EM, Chiu I, Li J, Verna N, Vorup-Jensen T, Kessler B, Shimaoka M, Chan R, Friend D, Mahmood U, Weissleder R, Moore RD, Carrol MC. J Exp Med. 2006;203(1):141-52.

60. Bouvet Zouali M. Silent antibodies. Arch Inst Pasteur Tunis. 2005;83:3-8

61. Carrol MC, Holers VM. Innate autoimmunity. Adv Immunol. 2005;86:137-57.

62. Fleming SD. Natural antibodies, autoantibodies and complement activation in tissue injury. Autoimmunity. 2006;39:379-86.

63. Stahel PF, Smith WR, Moore EE. Role of biological modifiers regulating the immune response after trauma. Injury. 2007;38:1409-22.

64. Schmidt OI, Infanger M, Heyde CE, Ertel W, Stahel PF. The role of neuroinflammation in traumatic brain injury. Eur J Trauma. 2004;30:135-49.

65. Sugimoto K, Hirata M, Majima M, Katori M, Ohwada T. Evidence for a role of kallikrein-kinin system in patients with shock after blunt trauma. Am J Physiol. 1998;274:1556-60.

66. Van Gils JM, Zwaginga JJ, Hordijk PL. Molecular and functional interactions among monocytes, platelets, and endothelial cells and their relevance for cardiovascular diseases. J Leukoc Biol. 2009;85:195-204.

67. Jenne CN, Urrutia R, Kubes P. Platelets: bridging hemostasis, inflammation and immunity. Int J Lab Hematol. 2013;35: 254-61.

68. Abraham E. Coagulation abnormalities in acute lung injury and sepsis. Am J Respir Cell Mol Biol. 2000;22:401-4.

69. Fan J, Kapus A, Li YH, Rizoli S, Marshall JC, Rotstein OD. Priming for enhanced alveolar fibrin deposition after hemorrhagic shock: role for tumor necrosis factor. Am J Respir Cell Mol Biol. 2000;22(4):412-21. 
70. Levi M, de Jonge E, Van der Poll T. New treatment strategies for disseminated intravascular coagulation based on current understanding of the pathophysiology. Ann Med. 2004;36:41-9.

71. Gando S, Kameue T, Matsuda N, Sawamura A, Hayakawa M, Kato H. Systemic inflammation and disseminated intravascular coagulation in early stage of ALI and ARDS: role of neutrophil and endothelial activation. Inflammation. 2004;28(4): 237-44.

72. Lo EH, Wang X, Cuzner ML. Extracellular proteolysis in brain injury and inflammation: role for plasminogen activators and matrix metalloproteinases. J Neurosci Res. 2002;69:1-9.

73. Whicher JT, Westacott CI. The acute phase response. In: Whicher JT, Evans SW, editors. Biochemistry of inflammation. London: Kluwer Academic; 1992. p. 243-71.

74. Du Clos TW. Function of C-reactive protein. Ann Med. 2000;32:274-8.

75. Zweigner J, Gramm HJ, Singer OC, Wegscheider K, Schumann RR. High concentrations of lipopolysaccharide-binding protein in serum of patients with severe sepsis or septic shock inhibit the lipopolysaccharide response in human monocytes. Blood. 2001;98(13):3800-8.

76. Fujishima S, Aikawa N. Neutrophil-mediated tissue injury and its modulation. Intensive Care Med. 1995;21:277-85.

77. Laroux FS, Pavlick KP, Hines IN, Kawachi S, Harada H, Bharwani S, Hoffman JM, Grisham MB. Role of nitric oxide in inflammation. Acta Physiol Scand. 2001;173(1):113-8.

78. Mosmann TR, Sad S. The expanding universe of T-cell subsets: Th1 and Th2 and more. Immunol Today. 1996;17:138-46.

79. Blanchette J, Jaramillo M, Olivier M. Signalling events involved in interferon-gamma-inducible macrophage nitric oxide generation. Immunology. 2003;108(4):513-22.

80. Kelso A. Th1 and Th2 subsets: paradigms lost? Immunol Today. 1995;16:374-9.

81. Monneret G, Debard AL, Venet F, Bohe J, Hequet O, Bienvenu J, Lepape A. Marked elevation of human circulating $\mathrm{CD} 4^{+} \mathrm{CD} 25^{+}$ regulatory $\mathrm{T}$ cells in sepsis induced immunoparalysis. Crit Care Med. 2006;34:2561-6.

82. Venet F, Pachot A, Debard AL, Bienvenu J, Lepape A, Powell WS, Monneret G. Human $\mathrm{CD} 4{ }^{+} \mathrm{CD} 25^{+}$regulatory T lymphocytes inhibit lipopolysaccharide-induced monocyte survival through a Fas/Fas ligand-dependent mechanism. J Immunol. 2006;177(9): 6540-7.

83. Romani L. Immunity to fungal infections. Nat Rev Immunol. 2011;11:275-88.

84. Blaschitz C, Raffatellu M. Th17 cytokines and the gut mucosal barrier. J Clin Immunol. 2010;30(2):196-203.

85. Van de Veerdonk FL, Mouktaroudi M, Ramakers BP, Pistiki A, Pickkers P, van der Meer JWM, Netea MG, GiammarellosBourboulis EJG. Deficient candida-specific T-helper 17 response during sepsis. J Infect Dis. 2012;206:1798-802.

86. Pachot A, Monneret G, Voirin N, Leissner P, Venet F, Bohé J, Payen D, Bienvenu J, Mougin B, Lepape A. Longitudinal study of cytokine and immune transcription factor mRNA expression in septic shock. Clin Immunol. 2005;114(1):61-9.

87. Tschoeke SK, Ertel W. Immunoparalysis after multiple trauma. Injury. 2007;38:1346-57.

88. Rossato M, Curtale G, Tamassia N, Castellucci M, Mori L, Gasperini S, Mariotti B, De Luca MC, Mirolo M, Cassatella MA, Locati M, Bazzoni F. IL-10-induced micro-RNA-187 negatively regulates TNF-alpha, IL-6 and IL-12p40 production in TLR4-stimulated monocytes. Proc Natl Acad Sci U S A. 2012;109:E3101-10.

89. Monneret G, Lepape A, Voirin N, Bohé G, Venet F, Debard AL, Thizy H, Bienvenu J, Gueyffier F, Vanhems P. Persisting low monocyte human leukocyte antigen-DR expression predicts mortality in septic shock. Intensive Care Med. 2006;32:1175-83.
90. Schouten M, Wiersinga WJ, Levi M, van der Poll T. Inflammation endothelium and coagulation in sepsis. $\mathrm{J}$ Leukoc Biol. 2008;83(3):536-45.

91. Bajaj MS, Tricomi SM. Plasma levels of the three endothelialspecific proteins von Willebrand factor, tissue factor pathway inhibitor, and thrombomodulin do not predict the development of acute respiratory distress syndrome. Intensive Care Med. 1999;25:1259-66.

92. Kayal S, Jais JP, Aguini N, Chaudiere J, Labrousse J. Elevated circulating E-selectin, intercellular adhesion molecule 1, and von Willebrand factor in patients with severe infection. Am J Respir Crit Care Med. 1998;157:776-84.

93. Leclerc J, Pu Q, Corseaux D, Haddad E, Decoene C, Bordet R, Six I, Jude B, Vallet B. A single endotoxin injection in the rabbit causes prolonged blood vessel dysfunction and a procoagulant state. Crit Care Med. 2000;28:3672-8.

94. Wiel E, Vallet B. Vascular endothelial cell dysfunction in septic shock. Crit Care Med. 2001;29(Suppl):S36-41.

95. Bombeli T, Mueller M, Haeberli A. Anticoagulant properties of the vascular endothelium. Thromb Haemost. 1997;77:408-23.

96. Rapaport S, Rao L. Initiation and regulation of tissue factor-dependent blood coagulation. Arterioscler Thromb. 1992;12:1111-21.

97. Ott I, Miyagi Y, Miyazaki K, Heeb MJ, Mueller BM, Rao LV, Ruf W. Reversible regulation of tissue factor-induced coagulation by glycosyl phosphatidylinositol-anchored tissue factor pathway inhibitor. Arterioscler Thromb Vasc Biol. 2000;20(3):874-82.

98. Monroe DM, Key NS. The tissue factor-factor VIIa complex: procoagulant activity, regulation, and multitasking. J Thromb Haemost. 2007;5:1097-105.

99. Esmon CT. Protein C anticoagulant pathway and its role in controlling microvascular thrombosis and inflammation. Crit Care Med. 2001;29:S48-51.

100. Binder BR, Christ G, Gruber F, Grubic N, Hufnagl P, Krebs M, Mihaly J, Prager GW. Plasminogen activator inhibitor 1: physiological and pathophysiological roles. News Physiol Sci. 2002;17(2):56-61.

101. Regoeczi E, Brain MC. Organ distribution of fibrin in disseminated intravascular coagulation. Br J Haematol. 1969;17:73-81.

102. Carr C, Bild GS, Chang AC. Recombinant E. coli-derived tissue factor pathway inhibitor reduces coagulopathic and lethal effects in the baboon gram-negative model of septic shock. Circ Shock. 1994;44:126-37.

103. Camerota AJ, Creasey AA, Patla V, Larkin VA, Fink MP. Delayed treatment with recombinant human tissue factor pathway inhibitor improves survival in rabbit gram-negative peritonitis. J Infect Dis. 1998;177:668-76.

104. Springer T. Traffic signals on endothelium for lymphocyte recirculation and leukocyte emigration. Annu Rev Physiol. 1995;57:827-72.

105. Varani J, Ward P. Mechanisms of endothelial cell injury in acute inflammation. Shock. 1994;2:311-9.

106. Doerschuk CM. Leukocyte trafficking in alveoli and airway passage. Respir Res. 2000;1:136-40.

107. Levi M, van der Poll T. Endothelial injury in sepsis. Intensive Care Med. 2013;39:1839-42.

108. Riewald M, Ruf W. Mechanistic coupling of protease signaling and initiation of coagulation by tissue factor. Proc Natl Acad Sci U S A. 2001;98:7742-7.

109. Riewald M, Petrovan RJ, Donner A, Mueller BM, Ruf W. Activation of endothelial cell protease activated receptor 1 by the protein C pathway. Science. 2002;296:1880-2.

110. Kimura K, Ito M, Amano M, Chihara K, Fukata Y, Nakafuku M, Yamamori B, Feng J, Nakano T, Okawa K, Iwamatsu A, Kaibucki K. Regulation of myosin phosphatase by Rho and Rho-associated kinase (Rho-kinase). Science. 1996;273:245-8. 
111. Bhagat K, Moss R, Collier J, Vallance P. Endothelial "stunning" following a brief exposure to endotoxin: a mechanism to link infection and infarction? Cardiovasc Res. 1996;32:822-9.

112. Sandow SL, Hill CE. Incidence of myoendothelial gap junctions in the proximal and distal mesenteric arteries of the rat is suggestive of a role in endothelium-derived hyperpolarizing factormediated response. Circ Res. 2000;86:341-6.

113. Emerson GG, Segal SS. Endothelial cell pathway for conduction of hyperpolarization and vasodilation along hamster feed artery. Circ Res. 2000;86:94-100.

114. Segal SS. Microvascular recruitment in hamster striated muscle: role for conducted vasodilation. Am J Physiol. 1991;261:H180-9.

115. Pinsky MR. Regional blood flow distribution. In: Pinsky MR, Dhainaut JF, Artigas A, editors. The splanchnic circulation: no longer a silent partner. Berlin: Springer; 1995. p. 1-13.

116. Nelson DP, Samsel RW, Wood LDH, Schumacker PT. Pathological supply dependence of systemic and intestinal $\mathrm{O} 2$ uptake and endotoxemia. J Appl Physiol. 1988;64:2410-9.

117. Lam C, Tyml K, Martin C, Sibbald W. Microvascular perfusion is impaired in a rat model of normotensive sepsis. J Clin Invest. 1994;94(5):2077-83.

118. Humer MF, Phang PT, Friesen BP, Allard MF, Goddard CM, Walley KR. Heterogeneity of gut capillary transit times and impaired gut oxygen extraction in endotoxemic pigs. J Appl Physiol. 1996;81:895-904.

119. Elis CG, Bateman RM, sharpe MD, Sibbald WJ, Gill R. Effect of a maldistribution of microvascular blood flow on capillary O2 extraction in sepsis. Am J Physiol Heart Circ Physiol. 2002;282:H156-64.

120. Eigenbrod T, Park JH, Harder J, Iwakura Y, Nunez G. Cutting edge: critical role of mesothelial cells in necrosis-induced inflammation through the recognition of IL-1 alpha released from dying cells. J Immunol. 2008;181:8194-8.

121. Dinarello CA. Interleukin-1 in the pathogenesis and treatment of inflammatory diseases. Blood. 2011;117:3720-32.

122. Koppelman B, Neefjes JJ, de Vries JE, de Waal Malefyt R. Interleukin-10 down regulates MHC class II alphabeta peptide complexes at the plasma membrane of monocytes by affecting arrival and recycling. Immunity. 1997;7:861-71.

123. Giannoudis PV, Smith RM, Perry SL, Windsor AJ, Dickson RA, Bellamy MC. Immediate IL-10 expression following major orthopaedic trauma. Relationship to anti-inflammatory response and subsequent development of sepsis. Intensive Care Med. 2000;26:1076-81.

124. Galbraith N, Walker S, Galandiuk S, Gardner S, Polk HC Jr. The significance and challenges of monocyte impairment: for the patient and the surgeon. Surg Infect. 2016;17:303-12.

125. Hotchkiss RS, Tinsley KW, Swanson PE, Grayson MH, Osborne D, Wagner TH, Cobb JP, Coppersmith C, Karl IE. Depletion of dendritic cells, but not macrophages, in patients with sepsis. J Immunol. 2002;168:2493-500.

126. Wesche DE, Lomas-Neira JL, Perl M, Chung CS, Ayala A. Leukocyte apoptosis and its significance in sepsis and septic shock. J Leukoc Biol. 2005;78:325-37.

127. Delogu G, Moretti S, Antonucci A. Apoptosis and surgical trauma: dysregulated expression of death and survival factors on peripheral lymphocytes. Arch Surg. 2000;135:1141-7.

128. Danial NN, Korsmeyer SJ. Cell death: critical control points. Cell. 2004;116:205-19.

129. Zimmermann KC, Green DR. How cells die: apoptosis pathways. J Allergy Clin Immunol. 2001;108:S99-S103.

130. Pop C, Salvesen GS. Human caspases: activation, specificity, and regulation. J Biol Chem. 2009;284:21777-81.

131. Pinheiro da Silva F, Nizet V. Cell death during sepsis: integration of disintegration in the inflammatory response to overwhelming infection. Apoptosis. 2009;14:509-21.
132. Melino G. The sirens' song. Nature. 2001;412:23.

133. Jimenez MF, Watson RW, Parodo J, Evans D, Foster D, Steinberg M, Rotstein OD, Marshall JC. Dysregulated expression of neutrophil apoptosis in the systemic inflammatory response syndrome. Arch Surg. 1997;132:1263-70.

134. Hotchkiss RS, Swanson PE, Freeman BD, Tinsley KW, Cobb JP, Matischak GM, Buchman TG, Karl IE. Apoptotic cell death in patients with sepsis, shock and multiple organ dysfunction. Crit Care Med. 1999;27:1230-51.

135. Felmet KA, Hall MW, Clark RS, Jaffe R, Carcillo J. Prolonged lymphopenia, lymphoid depletion and hypoprolactinemia in children with nosocomial sepsis and multiple organ failure. J Immunol. 2005;174:3765-72.

136. Hotchkiss RS, Schmieg RE Jr, Swanson PE, Freeman BD, Tinsley KW, Cobb JP, Karl IE, Buchman TG. Rapid onset of intestinal epithelial and lymphocyte apoptotic cell death in patient with trauma and shock. Crit Care Med. 2000;28:3207-17.

137. Fink MP, Evans TW. Mechanisms of organ dysfunction in critical illness: report from a round table conference held in Brussels. Intensive Care Med. 2002;28:369-75.

138. Abraham E, Singer M. Mechanisms of sepsis-induced organ dysfunction. Crit Care Med. 2007;35:2408-16.

139. Hotchkiss RS, Monneret G, Payen D. Sepsis-induced immunosuppression: from cellular dysfunctions to immunotherapy. Nat Rev Immunol. 2013;13:862-74.

140. Meakins JL, Pietsch JB, Bubenick O, Kelly R, Rode H, Gordon J, MacLean LD. Delayed hypersensitivity: indicator of acquired failure of host defenses in sepsis and trauma. Ann Surg. 1977; 186:241-50.

141. Luyt CE, Combes A, Deback C, Aubriot-Lorton MH, Nieszkkowska A, Trouillet JL, Capron F, Agut H, Gilbert C, Chastre J. Herpes simplex virus lung infection in patients undergoing prolonged mechanical ventilation. Am J Respir Crit Care Med. 2007;175(9):935-42.

142. Limaye AP, Kirby KA, Rubenfeld GD, Leisenring WM, Bulger EM, Neff MJ, Gibran NS, Huang ML, Santo Hayes TK, Corey L, Boeckh M. Cytomegalovirus reactivation in critically immunocompetent patients. JAMA. 2008;300:413-22.

143. Otto GP, Sossdorf M, Claus RA, Rodel J, Menge K, Reinhardt K, Bauer M, Riedemann NC. The late phase of sepsis is characterized by an increased microbiological burden and death rate. Crit Care. 2011;15(4):R183.

144. Kollef KE, Schramm GE, Wills AR, Reichley RM, Micek ST, Kollef MH. Predictors of 30-day mortality and hospital costs in patients with ventilator-associated pneumonia attributed to potentially antibiotic-resistant gram-negative bacteria. Chest. 2008;134:281-7.

145. Cavaillon M, Adib-Conquy M. Bench to bedside review: endotoxin tolerance as a model of leukocyte reprogramming in sepsis. Crit Care. 2006;10:233. https://doi.org/10.1186/cc5055.

146. Biswas SK, Lopez-Collazo E. Endotoxin tolerance: new mechanisms, molecules and clinical significance. Trends Immunol. 2009;30:475-87.

147. Zhang X, Morrison DC. Lipopolysaccharide structure-function relationship in activation versus reprogramming of mouse peritoneal macrophages. J Leukoc Biol. 1993;54:444-50.

148. Boomer JS, To K, Chang KC, Takasu O, Osborne DF, Walton AH, Bricker TL, Jarman SD II, Kreisel D, Krupnick AS, Srivastava A, Swanson PE, Green JM, Hotchkiss RS. Immunosuppression in patients who die of sepsis and multiple organ failure. JAMA. 2011;306:2594-605.

149. Morre M, Beq S. Interleukin-7 and immune reconstitution in cancer patients: a new paradigm for dramatically increasing overall survival. Target Oncol. 2012;7:55-68.

150. Levy Y, Sereti I, Tambussi G, Routy JP, Leliévre JD, Delfraissy JF, Molina JM, Fischl M, Goujard C, Rodriguez B, Rouzioux C, 
Avettand-Fenoel V, Croughs T, Beq S, Morre M, Poulin JF, Sekaly RP, Thiebaut R, Lederman MM. Effects of recombinant human interleukin-7 on T-cell recovery and thymic output in HIV-infected patients receiving antiretroviral therapy: result of a phase I/IIa randomized, placebo-controlled, multicenter study. Clin Infect Dis. 2012;55:291-300.

151. Hotchkiss RS, Swanson PE, Knudson CM, Chang KC, Cobb JP, Osborne DF, Zollner KM, Buchman TG, Korsemeyer SJ, Karl IE. Overexpression of Bcl-2 in transgenic mice decreases apoptosis and improves survival in sepsis. J Immunol. 1999;162:4148-56.

152. Venet F, Foray AP, Villars-Mechin A, Malcus C, Poitevin-Later F, Lepape A, Monneret G. IL-7 restores lymphocyte function in septic patients. J Immunol. 2012;189:5073-81.

153. Usinger J, McGlynn M, Kasten KR, Hoekzema AS, Watanabe E, Muenzer JT, McDonough JS, Tschoep J, Ferguson TA, McDunn JE, Morre M, Hildeman DA, Caldwell CC, Hotchkiss RS. IL-7 promotes $\mathrm{T}$ cell viability, trafficking, and functionality and improves survival in sepsis. J Immunol. 2010;184:3768-79.

154. Cheadle WG, Pemberton RM, Robinson D, Livingstone DH, Rodriguez JL, Polk HC Jr. Lymphocyte subset responses to trauma and sepsis. J Trauma. 1993;35:844-9.

155. Gouel-Cheron A, Venet F, Allaouchiche B, Monneret G. CD4+ T-lymphocyte alterations in trauma patients. Crit Care. 2012;16:432.

156. Le Tulzo Y, Pangault C, Gacouin A, Guilloux V, Tribut O, Amiot L, Tattevin P, Thomas R, Fauchet R, Drenou B. Early circulating lymphocyte apoptosis in human septic shock is associated with poor outcome. Shock. 2002;18:487-94.

157. Venet F, Davin F, Guignant C, Larue A, Cazalis MA, Darbon R, Allombert C, Mougin B, Malcus C, Poitevin-Later F, Lepape A. Early assessment of leukocyte alterations at diagnosis of septic shock. Shock. 2010;34(4):358-63.

158. Monneret G, Venet F, Kullberg BJ, Netea MG. ICU-acquired immunosuppression and the risk for secondary fungal infections. Med Mycol. 2011;49(Suppl 1):S17-23.

159. Venet F, Chung CS, Monneret G, Huang X, Horner B, Garber M, Ayala A. Regulatory $\mathrm{T}$ cell populations in sepsis and trauma. $\mathrm{J}$ Leukoc Biol. 2008;83(3):523-35.

160. Leng FY, Liu JL, Liu ZJ, Qu HP. Increased proportion of CD4(+) $\mathrm{CD} 25(+) F o x p 3(+)$ regulatory $\mathrm{T}$ cells during the early-stage sepsis in ICU patients. J Microbiol Immunol Infect. 2013;46(5): 338-44.

161. Delano MJ, Scumpia PO, Weinstein JS, Coco, Nagaraj S, KellyScumpia KM, O’Malley KA, Wynn JL, Antonenko S, Al-Quran SZ, Swan R, Chung CS, Atkinson MA, Ramphal R, Gabrilovich DJ, Reeves W, Ayala A, Phillips J, Laface D, Heyworth PG, ClareSalzler M, Moldawer LL. J Exp Med. 2007;204(6):1463-74.

162. Drifte G, Dunn-Siegrist I, Tissieres P, Pugin J. Innate immune functions of immature neutrophils in patients with sepsis and severe systemic inflammatory response syndrome. Crit Care Med. 2013;41:820-32.

163. Alves-Filho JC, Spiller F, Cunha FQ. Neutrophil paralysis in sepsis. Shock. 2010;34(Suppl 1):15-21.

164. Kovach MA, Standiford TJ. The function of neutrophils in sepsis. Curr Opin Infect Dis. 2012;25:321-7.

165. Cummings CJ, Martin TR, Frevert CW, Quan JM, Wong VA, Mongovin SM, Hagen TR, Steinberg KP, Goodman RB. Expression and function of the chemokine receptor CXCR1 and CXCR2 in sepsis. J Immunol. 1999;162(4):2341-6.

166. Kasten KR, Muenzer JT, Caldwell CC. Neutrophils are significant producers of IL-10 during sepsis. Biochem Biophys Res Commun. 2010;393:28-31.

167. Pillay J, Kamp VM, van Hoffen E, Visser T, Tak T, Lammers JW, Ulfman LH, Leenen LP, Pickkers P, Koenderman L. A subset of neutrophils in human systemic inflammation inhibits $\mathrm{T}$ cell responses through Mac-1. J Clin Invest. 2012;122:327-36.
168. Makarenkova VP, Bansal V, Matta BM, Perez LA, Ochoa JB. CD11+/Gr-1+ myeloid suppressor cells cause T cell dysfunction after traumatic stress. J Immunol. 2006;176(4):2085-94.

169. Souza-Fonseca-Guimaraes F, Parlato M, Phillipart F, Misset B, Cavaillon JM, Adib-Conquy M. Captain study group. Toll-like receptors expression and interferon-gamma production by $\mathrm{NK}$ cells in human sepsis. Crit Care. 2012;16:R206.

170. Andreu-Ballester JC, Tormo-Calandin C, Garcia-Ballestreros C, Perez-Griera J, Amigò V, Almela-Quilis A, Ruiz del Castillo J, Penarroja-Otero C, Ballester. Association of $\Upsilon \delta$ Tcells with disease severity and mortality in septic patients. Clin Vaccine Immunol. 2013;20(5):738-46.

171. Singer PM, De Santis V, Vitale D, Jeffcoate W. Multiorgan failure is an adaptive, endocrine-mediated, metabolic response to overwhelming systemic inflammation. Lancet. 2004;364:545-8.

172. Mizock BA. The multiple organ dysfunction syndrome. Dis Mon. 2009;55:476-526.

173. Moore FA, Moore EE. Evolving concepts in the pathogenesis of postinjury multiple organ failure. Surg Clin North Am. 1995;75:257-77.

174. MacFie J. Current status of bacterial translocation as a cause of surgical sepsis. Br Med Bull. 2004;71:1-11.

175. Umegaki T, Ikai H, Imanaka Y. The impact of acute organ dysfunction on patients' mortality with severe sepsis. J Anaesthesiol Clin Pharmacol. 2011;27:180-4.

176. Angus DC, Linde-Zwirble WT, Lidicker J, Clermont G, Carcillo J, Pinsky MR. Epidemiology of severe sepsis in the United States: analysis of incidence, outcome and associated costs of care. Crit Care Med. 2001;29:1303-10.

177. Danai PA, Moss M, Mannino DM, Martin GS. The epidemiology of sepsis in patients with malignancy. Chest. 2006;129(6): 1432-40.

178. Esper AM, Moss M, Lewis CA, Nisbet R, Mannino DM, Martin GS. The role of infections and comorbidity. Factors that influence disparities in sepsis. Crit Care Med. 2006;34(10):2576-82.

179. Angus DC. The lingering consequences of sepsis: the hidden public health disaster? JAMA. 2010;304:1833-4.

180. Chavan SS, Huerta PT, Robbiati S, Valdes-Ferrer SI, Ochani M, Dancho M, Frankfurt M, Volpe BT, Tracey KJ, Diamond B. HMGB1 mediates cognitive impairment in sepsis survivors. Mol Med. 2012;18:930-7.

181. Rothwell NJ, Hopkins SJ. Cytokines and the nervous system II: actions and mechanisms of action. Trends Neurosci. 1995;18:130-6.

182. Terrando N, Eriksson LI, Ryu JK, Yang T, Monaco C, Felmann M, Jonssson Fagerlund M, Charo IF, Akassoglou K, Maze M. Resolving postoperative neuroinflammation and cognitive decline. Ann Neurol. 2011;70:986-95.

183. Sonneville R, Verdonk F, Rauturier C, Klein IF, Wolff M, Annane D, Chretien F, Sharshar T. Understanding brain dysfunction in sepsis. Ann Intensive Care. 2013;3:1-11.

184. Lamar CD, Hurley RA, Taber KH. Sepsis-associated encephalopathy: review of neuropsychiatric manifestations and cognitive outcome. J Neuropsychiatry Clin Neurosci. 2011;23:237-41.

185. Sharshar T, Annane D, de la Grandmaison GL, Brouland GP, Hopkinson NS, Francoise G. The neuropathology of septic shock. Brain Pathol. 2004;14:21-33.

186. Sprung CL, Peduzzi PN, Shatney CH, Schein RM, Wilson ME, Sheagren JN, Hinshaw LB. Impact of encephalopathy on mortality in the sepsis syndrome. The veterans Administration Systemic Sepsis Cooperative Study Groups. Crit Care Med. 1990;18(8):801-6.

187. ARDS Definition Task Force, Ranieri VM, Rubenfeld GD, Thompson BT, Ferguson ND, Caldwell E, Fan E, Camporota L, Slutsky AS. Acute respiratory distress syndrome: the Berlin definition. JAMA. 2012;307(23):2526-33. 
188. Pelosi P, Caironi P, Gattinoni L. Pulmonary and extrapulmonary forms of acute respiratory distress syndrome. Semin Respir Crit Care Med. 2001;22:259-68.

189. Blank M, Napolitano LM. Epidemiology of ARDS and ALI. Crit Care Clin. 2011;27:439-58.

190. Woolf N. Chapter 33: Pulmonary edema (including respiratory distress syndrome). In: Pathology: basic and systemic. London: WB Saunders Ed; 1998. p. 446-51.

191. Muller NL, Frase RS, Colman NC, Paré PD. Chapter 14: Pulmonary edema. In: Radiologic diagnosis of diseases of the chest. London: WB Saunders Ed; 2001. p. 432-51.

192. Agarwal R, Srinivas R, Nath A. Is the mortality higher in the pulmonary vs the extrapulmonary ARDS? A meta-analysis. Chest. 2008; 133:1463-73.

193. The Acute Respiratory Distress Syndrome Network, Brower RG, Matthay MA, Morris A, Schoenfeld D, Thompson BT, Wheeler A. Ventilation with lower tidal volumes as compared with traditional tidal volumes for acute lung injury and the acute respiratory distress syndrome. N Engl J Med. 2000;342:1301-8.

194. Rohde JM, Odden AJ, Bonham C, Kuhn L, Malani P, Flanders S, Iwashyna TJ, Chen LM. The epidemiology of acute organ system dysfunction from severe sepsis outside the intensive care unit. J Hosp Med. 2013;8:243-7.

195. Ogura H, Gando S, Saitoh D, Takeyama N, Kushimoto S, Fujishima S, Mayumi T, Araki T, Ikeda H, Kotani J, Miki Y, Shiraishi S, Suzuki K, Suzuki Y, Takuma K, Tsuruta R, Yamaguchi Y, Yamashita N, Aikawa N. Epidemiology of severe sepsis in Japanese intensive care units: a prospective multicenter study. J Infect Chemother. 2014;20(3):157-62.

196. Guidet B, Aegerter P, Gauzit R, Meshaka P, Dreyfuss D, CUB-Réa Study Group. Incidence and impact of organ dysfunctions associated with sepsis. Chest. 2005;127:942-51.

197. Kumar A, Haery C, Parrillo JE. Myocardial dysfunction in septic shock: part 1. Clinical manifestation of cardiovascular dysfunction. J Cardiothorac Vasc Anesth. 2001;15(3):364-76.

198. Parker MM, Shelhamer JH, Bacharach SL, Green MV, Natanson C, Frederick TM, Damske BA, Parrillo JE. Profound but reversible myocardial depression in patients with septic shock. Ann Intern Med. 1984;100(4):483-90.

199. Hassoun SM, Marechal X, Montaigne D, Bouazza Y, Decoster B, Lancel S, Neviere R. Prevention of endotoxin-induced sarcoplasmic reticulum calcium leak improves mitochondrial and myocardial dysfunction. Crit Care Med. 2008;36:2590-6.

200. Kao YH, Chen YC, Cheng CC, Lee TI, Chen YJ, Chen SA. Tumor necrosis factor-alpha decreases sarcoplasmic reticulum $\mathrm{Ca} 2+-$ ATPase expressions via the promoter methylation in cardiomyocytes. Crit Care Med. 2009;38(1):217-22.

201. Stein B, Frank P, Schmitz W, Scholz H, Thoenes M. Endotoxin and cytokines induce direct cardiodepressive effects in mammalian cardiomyocytes via induction of nitric oxide synthase. J Mol Cell Cardiol. 1996;28(8):1631-9.

202. MacLean LD, Mulligan WG, McLean APH, Duff JH. Patterns of septic shock in man: a detailed study of 56 patients. Ann Surg. 1967;166:543-62.

203. Waisbren BA. Bacteremia due to gram-negative bacilli other than the Salmonella: a clinical and therapeutic study. Arch Intern Med. 1951;88(4):467-88.

204. Parker MM, McCarthy KE, Ognibene FP. Right ventricular dysfunction and dilatation, similar to left ventricular changes, characterize the cardiac depression of septic shock in humans. Chest. 1990;97:126-31.

205. Granger DN, Kvietys PR, Korthuis RJ. Microcirculation of the intestinal mucosa. In: Wood JD, editor. Handbook of physiology section 6 . The gastrointestinal system vol. 1: motility and circulation. Part II. American Physiological Society; 1989. p. 1405-74.
206. Granger HJ. Autoregulation of tissue perfusion and oxygenation. In: Kamada T, Shiga T, McCuskey RS, editors. Tissue perfusion and organ function: ischemia/reperfusion injury. Amsterdam: Elsevier-Science; 1996. p. 29-45.

207. Matta BF, Stow PJ. Sepsis-induced vasoparalysis does not involve the cerebral vasculature: indirect evidence from autoregulation and carbon dioxide reactivity studies. Br J Anaesth. 1996;76: 790-4.

208. Parker JL, Emerson TE Jr. Cerebral hemodynamics vascular reactivity and metabolism during canine endotoxin shock. Circ Shock. 1977;4:41-53.

209. McCormack DG. Control of vascular reactivity. New Horiz. 1995;3:248-56.

210. Scott JA, Machoun M, McCormack DG. Inducible nitric oxide synthase and vascular reactivity in rat thoracic aorta: effect of aminoguanidine. J Appl Physiol. 1996;80:271-7.

211. el-Dwairi Q, Comtois A, Guo Y, Hussain SN. Endotoxin induced skeletal muscle contractile dysfunction: contribution of nitric oxide synthases. Am J Physiol. 1998;274:C770-9.

212. Goddard CM, Poon BY, Khu ME, Wiggs BR, VanEden SF, Hogg JC. KR. Leukocyte activation does not mediate myocardial leukocyte retention during endotoxemia in rabbits. Am J Physiol. 1998;275:H1548-57.

213. Sutton ET, Norman JC, Newton CA, Hellermann GR, Richard IS. Endothelial structural integrity is maintained during endotoxic shock in an interleukin-1 type 1 receptor knockout mouse. Shock. 1997;7:105-10.

214. Tyml K, Yu J, McCormack DG. Capillary and arteriolar responses to local vasodilators are impaired in a rat model of sepsis. J Appl Physiol. 1998;84:837-44.

215. Vallet B. Vascular reactivity and tissue oxygenation. Intensive Care Med. 1998;24:3-11.

216. Lang CH, Bagby GJ, Ferguson JL, Spitzer JJ. Cardiac output and redistribution of organ blood flow in hypermetabolic sepsis. Am J Physiol. 1984;246:R331-7.

217. Mann KG, Van't Veer C, Cawthern K, Butenas S. The role of the tissue factor pathway in initiation of coagulation. Blood Coagul Fibrinolysis. 1998;9(Suppl):S3-7.

218. Ruf W, Edgington TS. Structural biology of tissue factor, the initiator of thrombogenesis in vivo. FASEB J. 1994;8:385-90.

219. Camerer E, Kolsto AB, Prydz H. Cell biology of tissue factor, the principal initiator of blood coagulation. Thromb Res. 1996;81:1-41.

220. Nieuwland R, Berckmans RJ, McGregor S, Boing AN, Romijn FP, Westendorp RG, Hack CE, Sturk A. Cellular origin and procoagulant properties of microparticles in meningococcal sepsis. Blood. 2000;83:861-7.

221. Bockmeyer CL, Claus RA, Budde U. Inflammation-associated ADAMTS13 deficiency promotes formation of ultra-large von Willebrand factor. Hematologica. 2008;93:137-40.

222. Osterud B. Tissue factor expression by monocytes: regulation and pathophysiological roles. Blood Coagul Fibrinolysis. 1998;9(Suppl):S9-S14.

223. Gando S. Microvascular thrombosis and multiple organ dysfunction syndrome. Crit Care Med. 2010;38(2 Suppl):S35-42.

224. Dhainault JF, Jan SB, Joyce DE, Pettila V, Basson BR, Brandt JT, Sundin D, Levi M. Treatment effects of drotrecogin alfa (activated) in patients with severe sepsis with or without overt disseminated intravascular coagulation. J Thromb Haemost. 2004;2: 1924-33.

225. Kobayashi N, Maekawa T, Takada M, Tanaka H, Gonmori H. Criteria for diagnosis of DIC based on the analysis of clinical and laboratory findings in 345 DIC patients collected by the Research Committee on DIC in Japan. Bibl Haematol. 1983;49:265-75. 
226. Taylor FB, Toh CH, Hoots WK, Wada H, Levi M. Towards definition, clinical and laboratory criteria, and a scoring system for disseminated intravascular coagulation. On behalf of the Scientific Subcommittee on Disseminated Intravascular Coagulation (DIC) of the International Society of Thrombosis and Haemostasis (ISTH). Thromb Haemost. 2001;86:1327-30.

227. Gando S, Iba T, Eguchi Y, Ohtomo Y, Okamoto K, Koseki K, Mayumi T, Murata A, Ikeda T, Ishikura H, Ueyama M, Ogura H, Kushimoto S, Saitoh D, Endo S, Shimazaki A. A multicenter, prospective validation of disseminated intravascular coagulation diagnostic criteria for critically ill patients: comparing current criteria. Crit Care Med. 2006;34:625-31.

228. Takemitsu T, Wada H, Hatada T, Ohmori Y, Ishikura K, Takeda T, Sugiyama T, Yamada N, Maruyama K, Katayama N, Isaji S, Shimpo H, Kusunoki M, Nobori T. Prospective evaluation of three different diagnostic criteria for disseminated intravascular coagulation. Thromb Haemost. 2011;105:40-4.

229. Aird WC. The hematologic system as a marker of organ dysfunction in sepsis. Mayo Clin Proc. 2003;78:869-81.

230. Brun-Buisson C, Doyon F, Carlet J, Dellamonica P, Gouin F, Lepoutre A, Mercier JC, Offenstadt G, Régnier B. Incidence, risk factors, and outcome of severe sepsis and septic shock in adults: a multicenter prospective study in intensive care unit. French ICU group for Severe Sepsis. JAMA. 1995;274:968-74.

231. Mavrommatis AC, Theodoridis T, Orfanidou A, Roussos C, Christopolou-Kokkinou V, Zakynthinos S. Coagulation system and platelets are fully activated in uncomplicated sepsis. Crit Care Med. 2000;28(2):451-7.

232. Parmar A, Langerberg C, Wan L, May CN, Bellomo R, Bagshaw SM. Epidemiology of sepsis acute kidney injury. Curr Drug Targets. 2009;10:1169-78.

233. Thakar CV, Christianson A, Freyberg R, Almenoff P, Render ML. Incidence and outcomes of acute kidney injury in intensive care units: a Veterans Administration Study. Crit Care Med. 2009;37(9):2252-8.

234. Hoste EA, Kellum JA. Incidence classification and outcomes of acute kidney injury. Contrib Nephrol. 2007;156:32-8.

235. Kellum JA, Levin N, Bouman C, Lameire N. Developing a consensus classification system for acute renal failure. Curr Opin Crit Care. 2002;8:509-14.

236. Bellomo R, Ronco C, Kellum JA, Metha RL, Palevsky P. Acute Dialysis Quality Initiative workgroup: acute renal failuredefinition, outcome measures, animal models, fluid therapy and information technology needs: the Second International Consensus Conference of the Acute Dialysis Quality Initiative (ADQI) Group. Crit Care. 2004;8:R204-12.

237. Langenberg C, Bagshaw SM, May CM, Bellomo R. The histopathology of septic acute kidney injury: a systematic review. Crit Care. 2008;12(2):R38.

238. Messmer UK, Winkel G, Briner VA, Pfeilschifter J. Glucocorticoids potently block tumor necrosis factor-alpha and lipopolysaccharide-induced apoptotic cell death in bovine glomerular endothelial cells upstream of caspase 3 activation. Br J Pharmacol. 1999;127:1633-40.

239. Langenberg C, Wan L, Egi M, May CN, Bellomo R. Renal blood flow distribution in experimental septic acute renal failure. Kidney Int. 2006;69:1996-2002.

240. Wan L, Bagshaw SM, Langenberg C, Saotome T, May C, Bellomo R. Pathophysiology of septic acute kidney injury: what do we really know? Crit Care Med. 2008;36(4 Suppl):S198-203.

241. Wan L, Langenberg C, Bellomo R, May CN. Angiotensin II in experimental hyperdynamic sepsis. Crit Care. 2009;13:R190.

242. Baud L, Oudinet JP, Bens M, Noe L, Peraldi MN, Rondeau E, Etienne J, Ardaillou R. Production of tumor necrosis factor by rat mesangial cells in response to bacterial lipopolysaccharide. Kidney Int. 1989;35(5):1111-8.
243. Uchino S, Kellum JA, Bellomo R, Doig GS, Morimatsu H, Morgera S, Schetz M, Tan I, Bouman C, Macedo E, Gibney N, Tolwani A, Ronco C. Beginning and Ending Supportive Therapy for the kidney (BEST Kidney). Acute renal failure in critically ill patients: a multinational multicenter study. JAMA. 2005;294:813-8.

244. Bagshaw SM, Lapinsky S, Dial S, Arabi Y, Dodek P, Wood G, Ellis P, Guzman J, Marshall J, Parrillo JE, Skrobik Y, Kumar A. Cooperative Antimicrobial Therapy of Sepstic Shock (CATSS) Database Research Group. Acute kidney injury in septic shock: clinical outcomes and impact of duration of hypotension prior to initiation of antimicrobial therapy. Intensive Care Med. 2009;35:871-81.

245. Podoll AS, Kozar R, Holcomb JB, Finkel KW. Incidence and outcome of early acute kidney injury in critically ill trauma patients. PLoS One. 2013;8:1-5.

246. Ulkeja A. Altered gastrointestinal motility in critically ill patients: current understanding of pathophysiology, clinical impact, and diagnostic approach. Nutr Clin Pract. 2010;25:16-25.

247. Chapman MJ, Nguyen NQ, Deane AM. Gastrointestinal dysmotility: clinical consequences and management of the critically ill patient. Gastroenterol Clin North Am. 2011;40:725-39.

248. Hayakawa M, Asahara T, Henzan N, et al. Dramatic changes of the gut flora immediately after severe and sudden insults. Dig Dis Sci. 2011;56:2361-5.

249. Guarner F, Malagelada JR. Gut flora in health and disease. Lancet. 2003;361:512-9.

250. Farrell CP, Barr M, Mullin JM, Mullin JM, Lande L, Zitin M. Epithelial barrier leak in gastrointestinal disease and multiorgan failure. J Epithel Biol Pharmacol. 2012;5:13-8.

251. Lautt WW. Mechanism and role of intrinsic regulation of hepatic arterial blood flow: hepatic arterial buffer response. Am J Physiol. 1985;249:G549-56.

252. Furhmann V, Kneidinger H, Herkner H, Heinz G, Nikfardjam M, Bojic A, Schellongowski P, Angermayr B, Kitzberger R, Warszawska J, Holzinger U, Schenk P, Madi C. Hypoxic hepatitis: underlying conditions and risk factors for mortality in cirtically ill patients. Intensive Care Med. 2009;35:1397-405.

253. Henrion J, Schapira M, Luwaert R, Colin L, Delanoy A, Heller FR. Hypoxic hepatitis: clinical and hemodynamic studies in 142 consecutive cases. Medicine (Baltimore). 2003;82:392-406.

254. Henrion J. Hypoxic hepatitis. Liver Int. 2012;32(7):1039-52.

255. Gimson AE. Hepatic dysfunction during bacterial sepsis. Intensive Care Med. 1987;13:162-6.

256. Banks JG, Foulis AK, Ledingham IM, MacSween RN. Liver function in septic shock. J Clin Pathol. 1982;35:1249-52.

257. Moreno R, Vincent JL, Matos R, Mendoca A, Cantraine F, Thijs L, Takala J, Sprung C, Antonelli M, Bruining H, Willats S. The use of maximum SOFA score to quantify organ dysfunction/failure in intensive care. Results of a prospective, multicenter study. Working Group on Sepsis relate Problems of the ESICM. Intensive Care Med. 1999;25:686-96.

258. Moseley RH. Sepsis and cholestasis. Clin Liver Dis. 2004;8:83-94.

259. Assimakopoulos SF, Scopa CD, Vagianos CE. Pathophysiology of increased intestinal permeability in obstructive jaundice. World $\mathbf{J}$ Gastroenterol. 2007;13:6458-64.

260. Kamiya S, Nagino M, Kanazawa H, Komatsu S, Mayumi T, Takagi K, Asahara T, Nomoto K, Tanaka R, Nimura Y. The value of bile replacement during external biliary drainage: an analysis of intestinal permeability, integrity, and microflora. Ann Surg. 2004:239:510-7.

261. Padillo FJ, Muntane J, Montero JL, Briceno J, Mino G, Solorzano G, Stiges-Serra A, Pera-Madrazo C. Effect of internal biliary drainage on plasma levels of endotoxin, cytokines, and C-reactive protein in patients with obstructive jaundice. World J Surg. 2002;26:1328-32. 
262. Fuchs M, Sanyal AJ. Sepsis and cholestasis. Clin Liver Dis. 2008;12:151-72.

263. Dellinger RP, Levy MM, Carlet JM, Bion J, Parker MM, Jaeschke R, Reinhart K, Angus DC, Brun-Buisson C, Beale R, Calandra T, Dhainaut JF, Gerlach H, Harvey M, Marini JJ, Marshall J, Ranieri M, Ramsay G, Sevransky J, Thompson BT, Townsend S, Vender JS, Zimmerman JL, Vincent JL. Surviving Sepsis Campaign: international guidelines for management of severe sepsis and septic shock: 2008. Crit Care Med. 2008;36:296-327.

264. McClave SA, Martindale RG, Vanek WW, McCarthy M, Roberts P, Taylor B, Ochoa JB, Napolitano L, Cresci G. Guidelines for the provision and assessment of nutrition support therapy in the adult critically ill patient: Society of Critical Care Medicine (SCCM) and American Society for Parenteral and Enteral Nutrition (A.S.P.E.N.). JPEN J Parenter Enteral Nutr. 2009;33:277-316. 